\title{
Mechanism of regulation of spliceosome activation by Brr2 and Prp8 and links to retinal disease
}

\section{Dissertation}

\author{
for the award of the degree \\ “Doctor of Philosophy” (Ph.D.) \\ in the Molecular Biology Program \\ Division of Mathematics and Natural Sciences \\ of the Georg-August-Universität Göttingen \\ submitted by
}

Sina Mozaffari-Jovin

born in

Sabzevar, Iran

Göttingen

2012 


\section{Members of the thesis committee:}

Prof. Dr. Reinhard Lührmann (Reviewer)

Department of Cellular Biochemistry, Max Planck Institute

for Biophysical Chemistry, Göttingen

Prof. Dr. Reinhard Jahn

Department of Neurobiology, Max Planck Institute

for Biophysical Chemistry, Göttingen

Prof. Dr. Ralf Ficner

Department of Molecular Structural Biology, Institute

for Microbiology and Genetics, Göttingen

Date of submission of Thesis: December, $14^{\text {th }}, 2012$ 
Affidavit

I declare that my Ph.D. thesis entitled "Mechanism of regulation of spliceosome activation by Brr2 and Prp8 and links to retinal disease" has been written independently and with no other sources and aids than quoted.

Sina Mozaffari-Jovin

Göttingen, 2012 
"The knowledge of anything,

since all things have causes,

is not acquired or complete

unless it is known by its causes"

\section{Avicenna}

(Father of Modern Medicine; c. 980- June 1037) 


\section{Table of Contents}

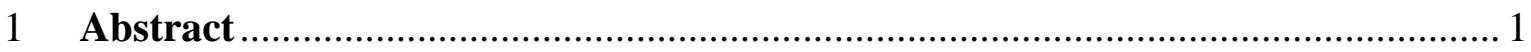

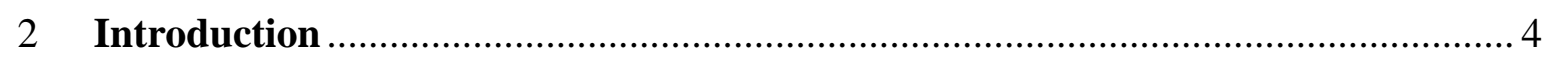

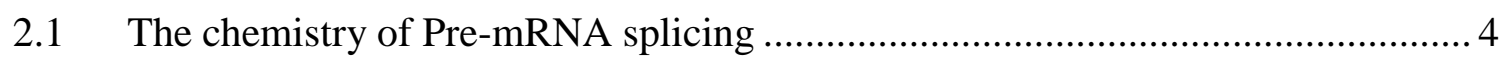

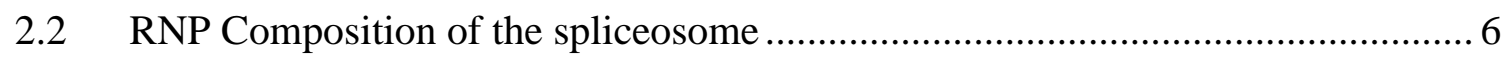

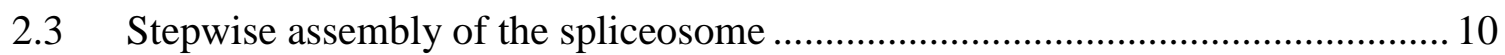

2.4 Rearrangements in the spliceosomal RNA-RNA network .................................. 12

2.5 RNA helicases as molecular motors of the spliceosome ..................................... 13

2.6 Characteristics of the conserved RNA helicase motifs....................................... 14

2.7 Mechanisms of nucleic acid strand separation by helicases ................................ 15

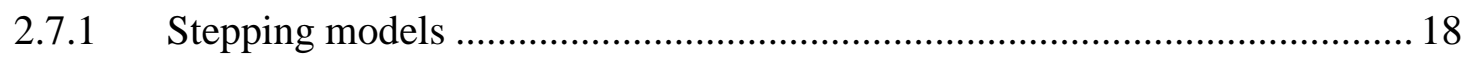

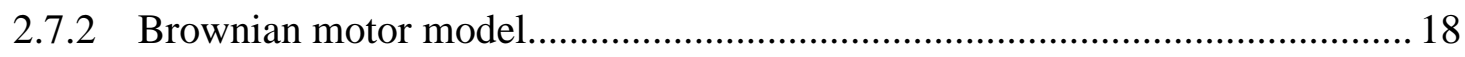

2.7.3 Local strand separation by DEAD-box RNA helicases .................................. 19

2.8 Regulation of RNA helicase activity by effector proteins ................................... 20

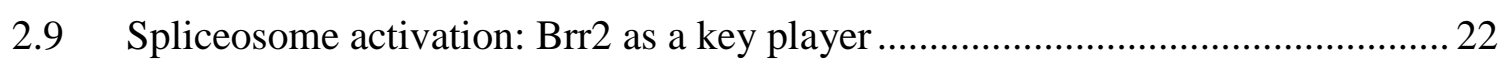

2.10 Impaired function of Brr2 leads to human retinal disease ................................ 24

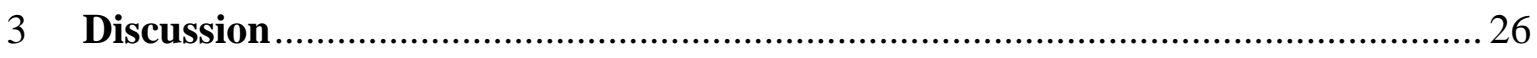

3.1 An initial structure-based working model of Brr2 RNA helicase........................ 27

3.2 The helical bundle domain of the N-Sec63 unit of Brr2 may act as a ratchet by

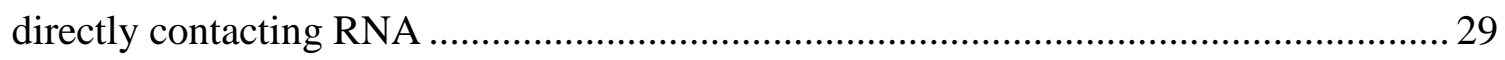

3.3 Brr2 consists of active $\mathrm{N}$-terminal and non-active C-terminal helicase cassettes 30

3.4 The C-terminal pseudohelicase domain of Brr2 acts as an intramolecular

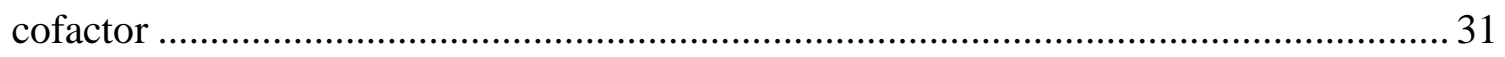

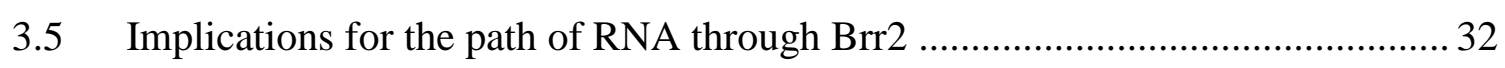

3.6 Mechanism of RNP remodeling by Brr2 during spliceosome activation .............. 33

3.7 The Prp8 RNase H-like domain interacts specifically with U4/U6 snRNA ......... 34

3.8 Mapping of the U4/U6 interaction site on the Prp8 RNase H domain ................. 35

3.9 A potential mechanism of Brr2 regulation by the Prp8 RNase $\mathrm{H}$ domain ........... 36

3.10 The Prp8 Jab1/MPN-like domain induces a locked conformation of Brr2 .......... 37

3.11 Molecular mechanism of Brr2 activation by the Prp8 Jab1/MPN domain........... 38

3.12 Molecular basis of the defects caused by the retinitis pigmentosa linked mutations

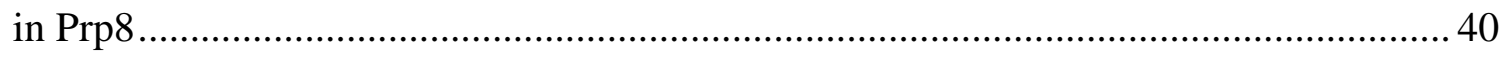

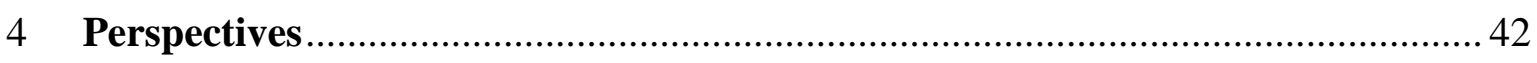

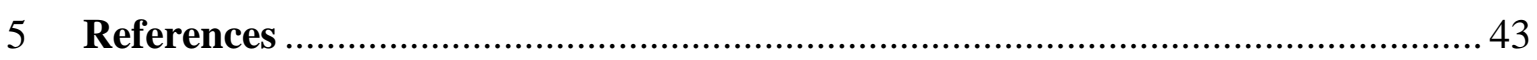




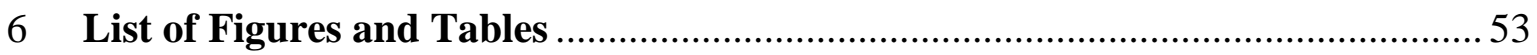

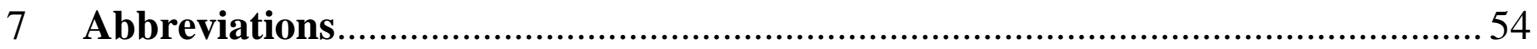

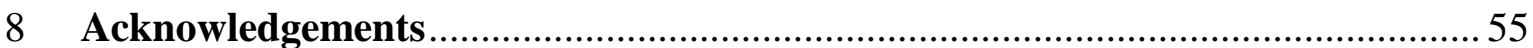

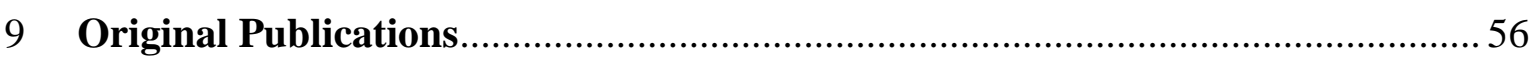

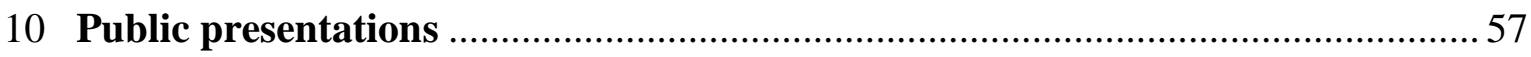




\section{Abstract}

Splicing is a crucial post-transcriptional processing event that entails the removal of noncoding intervening sequences (introns) from eukaryotic pre-mRNA and the ligation of the coding sequences (exons). It is carried out in a two-step reaction by the spliceosome, a giant and highly dynamic protein-rich ribonucleoprotein (RNP) enzyme. The spliceosome consists of five major subunits, U1, U2, U4/U6 and U5 snRNPs and multitude of nonsnRNP proteins. The active center of the spliceosome only develops de novo on the premRNA by a stepwise assembly of $\mathrm{U}$ snRNPs that is driven by several DExD/H-box ATPases/RNA helicases. Major structural and compositional rearrangements are required to render the spliceosome catalytically competent for promoting the two steps of splicing. The enzyme Brr2 plays a major role in this catalytic activation process. Brr2 is an exceptionally large DExH-box protein (ca. $250 \mathrm{kDa}$ ), and is a member of the Ski2-like RNA helicases in the spliceosome that stands out both structurally and functionally among other splicesosomal DExD/H-box proteins. It is composed of two putative helicase cassettes fused in tandem. Each helicase cassette contains conserved dual-RecA-like domains, flanked by a winged helix (WH) domain and a Sec63 homology unit of unknown function that may bestow specific properties upon the helicase. Brr2 is an integral component of the U5 snRNP and unlike other spliceosomal helicases it is preassembled with one of its substrates, the U4/U6 snRNPs, before recruitment to the pre-spliceosome. Furthermore, Brr2 remains stably associated with the splicesosome to function again during the disassembly step of the spliceosome. Thus, the RNPase activity of Brr2 needs to be reliably controlled to facilitate its multiple usages in the spliceosome. Indeed, Brr2 forms a stable complex with two U5 snRNP proteins, a large scaffolding protein Prp8 and the EF-2 like GTPase Snu114, both of which have been implicated in the regulation of Brr2 activity. In human, several mutations within Brr2 and the C-terminal tail of Prp8 cause a severe type of retinitis pigmentosa (RP), a progressive retinal dystrophy. It was hitherto unclear how Brr2 structurally and functionally adopts these capabilities and how the regulatory role of Prp8 on Brr2 can lead to a precise timing of the spliceosome activation and thus U4/U6 RNA unwinding by Brr2. In addition, the molecular basis of the way in which several RP-linked mutations in Brr2 and Prp8 may lead to the disease retinitis pigmentosa remained poorly understood. 
In this work, a crystal structure of the C-terminal Sec63 unit of Brr2 solved in collaboration with V. Pena and M. Wahl revealed the first insight into the structural similarity of the Brr2 helicase units with the DNA helicase Hel308. Guided by the Hel308 structure, the architecture of both Brr2 helicase cassettes could be modeled as a composite dual Hel308-like helicase. Functional roles for various predicted structural elements of Brr2 were then validated by mutational analysis in vitro and in living yeast cells. The results supported the idea that in analogy to Hel308 a conserved $\beta$-hairpin loop in the RecA-2 domain of the N-terminal helicase cassette may act as a strand separation device, during unwinding of U4/U6 RNAs.

More recently, the crystal structure of a larger fragment of human Brr2, encompassing both helicase cassettes, solved in collaboration with K. Santos and M. Wahl, revealed an extensive interaction surface between the C-terminal cassettes (respectively, Brr2 ${ }^{\mathrm{NC}}$ and $\mathrm{Brr} 2^{\mathrm{CC}}$ ), and provided a framework for a detailed structure-based mutational analysis of Brr's enzymatic activities. It could be shown that only the isolated $\mathrm{Brr}^{\mathrm{NC}}$ harbors ATPase and helicase activities and that it threads single-stranded RNA through a central tunnel and across a helix-loop-helix domain during duplex unwinding. Although the $\mathrm{Brr} 2^{\mathrm{CC}}$ is inactive on its own, it strongly stimulates the activity of the N-terminal cassette. Mutations of amino acid residues involved in the communication between the two cassettes, as well as mutations that interfere with the nucleotide-binding pocket of $\mathrm{Brr} 2^{\mathrm{CC}}$, strongly affected ATPase and/or helicase activities of the enzyme. Thus, while the $\mathrm{Brr} 2^{\mathrm{CC}}$ does not seem to engage RNA, it binds ATP and acts as an intramolecular cofactor to stimulate Brr ${ }^{\mathrm{NC}}$ helicase activity. Using various U4/U6 mutant constructs I was also able to show that Brr2 interacts with the single-stranded region of U4 preceding U4/U6 stem I (the U4 central domain), and translocates in a 3 ' to 5' direction along the U4 strand to unwind the U4/U6 stem I first.

In the second part of the work for this thesis I investigated the roles of the C-terminal RNase H-like (RH) and Jab1/MPN-like domains of Prp8 in the regulation of Brr's enzymatic functions. Using UV-induced RNA-protein crosslinking and RNA structure probing methods I could show that the RNase H domain of Prp8 forms a specific complex with U4/U6 snRNAs in vitro, where it binds to a single-stranded region of U4 preceding U4/U6 stem I. Using mass spectrometry, RNA-protein crosslinks could be mapped at the base of a hairpin loop ( $\beta$-finger) of the RH domain. Moreover, I was able to show that the Prp8 RNase $\mathrm{H}$ domain interferes with Brr2-mediated U4/U6 unwinding by sequestering 
Brr2's targeting site, indicating that the RH domain negatively regulates Brr2 function and acts as a keeper to prevent premature activation of the spliceosome. These findings also support the idea that the Prp8 RH domain acts as a platform for the handover of the 5'splice site from U1 to U6 snRNA prior to the activation step.

The Prp8 Jab1 domain is a ubiquitin-binding domain that comprises a globular domain followed by a protruding C-terminal tail, which is partly unstructured in the isolated Jab1 domain, and which represents a hotspot for mutations leading to retinitis pigmentosa. Using biochemical in vitro assays, I was able to show that the Jab1 domain binds only to the N-terminal helicase cassette and inhibits the helicase and ATPase activities of Brr2 by preventing Brr2 loading onto its RNA substrate U4/U6. Upon deletion of the unstructured C-terminal 16 amino acids, Jab1 ${ }^{\Delta 16}$ now strongly stimulated Brr2's ATPase and helicase activities, suggesting that the C-terminal tail of Jab1 may interfere with Brr2's RNA binding capacity. The crystal structure of Brr2 in complex with the intact Jab1 domain, which was obtained in collaboration with M. Wahl, revealed the molecular basis for the biochemical observations. Jab1 rests with its globular part primarily on the IG-like domain of $\mathrm{Brr}^{\mathrm{NC}}$ while the C-terminal tail interacts with the RNA binding motifs of the RecA domains, thus occluding the RNA binding tunnel of the N-terminal helicase cassette. I was also able to show that under conditions favoring RNA binding, the full-length Jab1 domain acts as a coactivator of Brr2, enhancing the coupling of ATP hydrolysis to duplex unwinding and the processivity of the helicase. This delicate regulation requires the dualcassette organization of Brr2 and is not observed with the isolated N-terminal helicase cassette. Finally, I have investigated the effect of various RP-linked mutations in the Prp8 Jab1 domain on the regulation of Brr2's activities in vitro and on the stability of tri-snRNP formation, cell viability and pre-mRNA splicing in vivo in yeast cells. Taken together, the results obtained uncover the mechanism underlying a unique dual-mode regulation of a superfamily 2 helicase by a protein cofactor and reveal that its disruption constitutes a disease principle underlying certain forms of retinitis pigmentosa. 


\section{Introduction}

\subsection{The chemistry of Pre-mRNA splicing}

A fundamental feature of all eukaryotic cells is that the primary transcripts of most of their coding genes undergo a variety of post-transcriptional modifications to produce the mature messenger RNAs (mRNAs). Only these properly processed mRNAs can be exported out of the nucleus and translated into polypeptides in the cytoplasm. One of the most important and intricate post-transcriptional modifications is pre-mRNA splicing that entails the removal of non-coding intervening sequences (introns) from precursor-messenger RNAs (pre-mRNAs) and the concomitant ligation of neighboring coding exons to generate continuous open reading frames for protein biosynthesis. This process is catalyzed by the spliceosome, a large and highly dynamic molecular ribonucleoprotein (RNP) machine that orchestrates the stepwise binding and release of numerous RNPs and protein factors.

The spliceosome catalyzes two $\mathrm{S}_{\mathrm{N}}$ 2-type trans-esterification reactions that involve three evolutionary conserved sequences, namely the 5'-splice site (5'ss), the branch point site (BPS) and the 3'-splice site (3'ss). First, the 5'ss is nucleophilically attacked by the 2'hydroxyl of a bulged adenosine of the BPS, which leads to formation of the excised 5'exon and an intermediate intron-lariat 3'-exon. The second step of splicing is carried out by attack of the free 3'-hydroxyl of the 5'-exon to the phosphodiester bond at the 3 'ss that generates the excised intron-lariat and the spliced exons (Figure 2.1; Villa et al., 2002; Green, 1986). The splice sites within the intron can be identified by consensus sequences in yeast and metazoans (Figure 2.2; Wahl et al., 2009). 


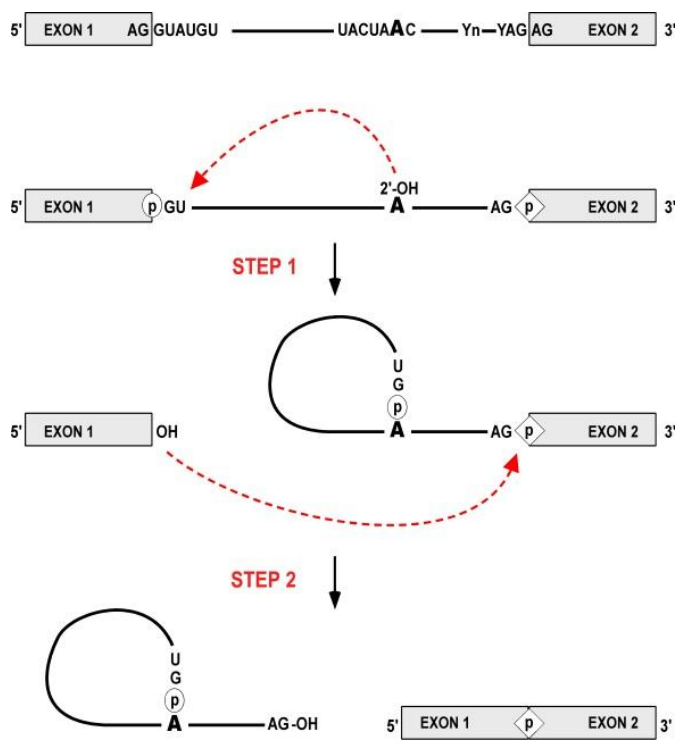

\section{Figure 2.1 Pre-mRNA splicing mechanism.}

Pre-mRNA splicing is accomplished by two consecutive nucleophilic reactions. First, the 2'hydroxl group of the branch point adenosine attacks the phosphodiester bond at the 5'ss leading to formation of a 2'-5' bond within the intron-lariat-3'exon and the excised 5' exon (magenta). Subsequently, in the second step of splicing, the free 3'-hydroxyl group of the 5'exon attacks the 3'ss that leads to the ligation of neighboring exons and excision of the intron-lariat (Figure kindly provided by Dr. Patrizia Fabrizio).

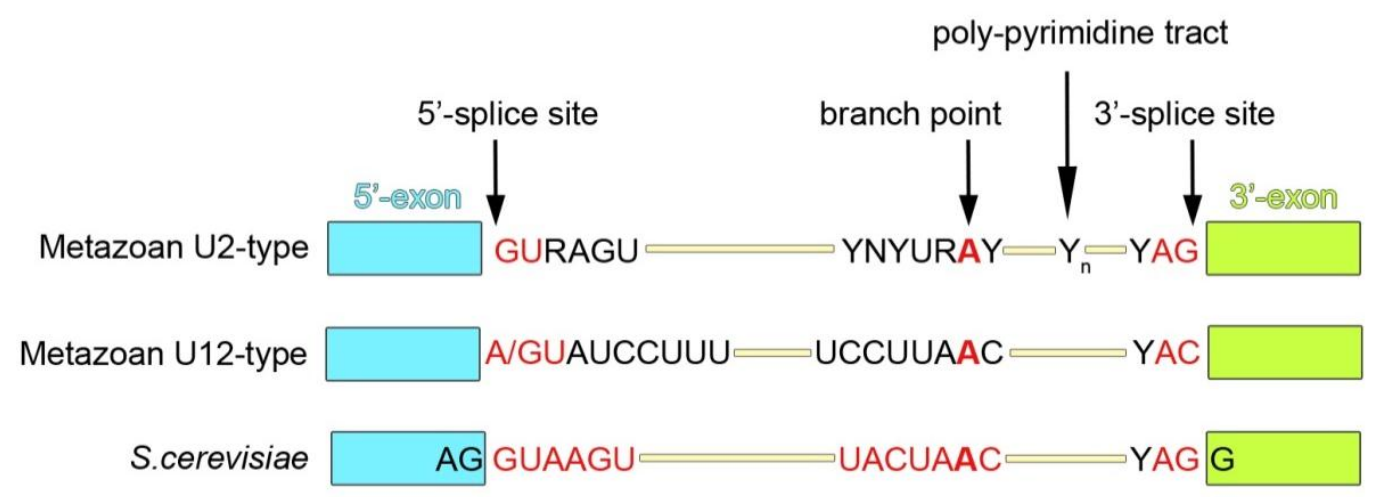

Figure 2.2 Consensus sequences of metazoan and yeast pre-mRNAs.

The 3' and 5' exons are separated by the intron (yellow) where the consensus 5'-splice site, branch point, 3'-splice site and poly-pyrimidine tract sequences in yeast and metazoan (both U2 and U12 types) are shown. $\mathrm{N}$ stands for any nucleotide, $\mathrm{R}$ for purine, and $\mathrm{Y}$ for pyrimidine. 
6 Introduction

\subsection{RNP Composition of the spliceosome}

The two-step splicing catalysis by the spliceosome involves sequential assembly of five small nuclear RNPs (snRNPs) designated U1, U2, U4, U5 and U6. In metazoans, there is a rare class of introns that are spliced by a different type of spliceosome (the so-called minor or U12-type spliceosome as opposed to the major or U2-type spliceosome). Minor spliceosomes are assembled from U11, U12, U4atac and U6atac snRNPs that are homologues of U1, U2, U4 and U6 snRNPs, respectively. The U5 snRNP is shared by both types of spliceosomes (Patel and Steitz, 2003; Tarn and Steitz, 1997). In metazoans, the BPS and the 3'ss are separated by a pyrimidine-rich stretch (the so-called poly-pyrimidine tract), which is not found in yeast or in U12-type introns (Figure 2.2).

The major spliceosome is formed from five uridine-rich RNPs (UsnRNPs), as the main building blocks and numerous non-snRNP splicing factors (Figure 2.3). Each UsnRNP is composed of a UsnRNA complexed with a set of seven Sm (B/B', D3, D2, D1, E, F, and G) or Sm-like (LSm2-8) proteins, and a number of UsnRNP-specific proteins (Raker et al., 1996). After transcription, all UsnRNAs, except U6, are 5'G-capped and 3'-end trimmed in the nucleus (Guthrie and Patterson, 1988). Differential 3'-end trimming of U5 in yeast creates two isoforms U5S and U5L whereas in human several U5 snRNA isoforms are formed. Further post-transcriptional modification of all UsnRNAs, with the exception of U6, takes place in the cytoplasm where the Sm ring is assembled on their Sm-site and the 5'G-cap is hypermethylated. A Sm-like (LSm) ring is also assembled on a 3'-region of U6 snRNA in the nucleus. Finally, UsnRNPs are re-imported into the nucleus and undergo further maturation through pseudouridylation and 2'-O-methylation in the Cajal bodies. However, 2'-O-methylation and pseudouridylation of the U6 snRNA is directed by snoRNAs in the nucleolus (Kiss, 2004; Kiss, 2001). Cajal bodies are also thought to be the site of assembly of the UsnRNP-specific proteins which is corroborated by the finding that proteins required for the assembly of the U2, the U4/U6 di-snRNP, and the U4/U6.U5 trisnRNP, are enriched within these nuclear bodies (Lemm et al., 2006; Makarova et al., 2002; Will and Lührmann, 2001). Within the human U4/U6 di-snRNP, the U4 and U6 snRNAs are extensively base paired and, in addition to the Sm and LSm core proteins, they stably bind to five U4/U6 di-snRNP specific proteins, 15.5K (hSnu13), CypH (20K), hPrp4 $(60 \mathrm{~K}), \mathrm{hPrp} 31(61 \mathrm{~K})$, and hPrp3 (90K) (Figure 2.4). The U5 snRNP contains the Sm proteins plus the large spliceosomal proteins hPrp8 (220K), hBrr2 (200K), hSnu114 (116K), and hPrp6 (102K), hPrp28 (100K), hLin1 (52K), 40K, hDib1 (15K) (hLin1 is not 
found in the U4/U6.U5 tri-snRNP). Three additional proteins, hSnu66 (110K), hSad1 $(65 \mathrm{~K})$, and $27 \mathrm{~K}$ are found in the tri-snRNP. The association of the U4/U6 di-snRNP with the U5 snRNP appears to be merely through protein-protein and/or RNA-protein interactions, as no intermolecular base pairing of U5 with U4/U6 is established. Indeed, based on two-hybrid data, hSnu66 (110K) and hPrp6 (102K) are thought to bridge these two snRNP particles of the tri-snRNP. All proteins of the tri-snRNP are highly evolutionarily conserved and all, except the $40 \mathrm{~K}, 27 \mathrm{~K}$ and $20 \mathrm{~K}$ proteins, have homologues in S.cerevisiae (Liu et al., 2006; Gottschalk et al., 1999; Stevens and Abelson, 1999).

In addition to $U$ snRNPs, splicing requires a multitude of non-snRNP protein factors that are not integral components of the snRNPs and may transiently associate with the spliceosome (Chen and Cheng, 2012). Among these proteins, SR proteins are a family of structurally related, essential splicing factors that play roles as activators of constitutive splicing and regulators of alternative splicing (reviewed in Graveley, 2000; Long and Caceres, 2009). The structural feature of the members of this family is the presence of one or two copies of an N-terminal RNA-recognition motif (RRM) followed by C-terminal arginine-serine (RS) di-peptide repeats. The RRM module recognizes RNA sequences and the RS domain mediates protein-protein interactions and can recruit splicing core factors to promote splicing. SF2/ASF (Splicing Factor2/Alternative Splicing Factor) and $\mathrm{U} 2 \mathrm{AF}^{65} / \mathrm{U} 2 \mathrm{AF}^{35}$ (U2 auxiliary factor) are examples of SR proteins that are essential components of the constitutive splicing machinery (Sanford et al., 2005; Krämer, 1996). There are at least eight different members of the DExD/H-box family of proteins that represent an abundant group of non-snRNP splicing factors that are essential for the constitutive splicing, though most of them only transiently associate with the spliceosome during the step that requires their function (Semlow and Staley, 2012). The function of this group of enzymes will be described in more details in the following sections. The Prp19 protein and its associated proteins that form the nineteen (NTC) complex in yeast or its human homologue the hPrp19/CDC5 complex, are another example of non-snRNP splicing factors that appears to associate with the spliceosome after recruitment of the U4/U6.U5 tri-snRNPs. This complex has been suggested to be involved in the activation process of the spliceosome, as its depletion stalls splicing prior to the first catalytic step (Ajuh et al., 2000; Makarova et al., 2004). 
8 Introduction
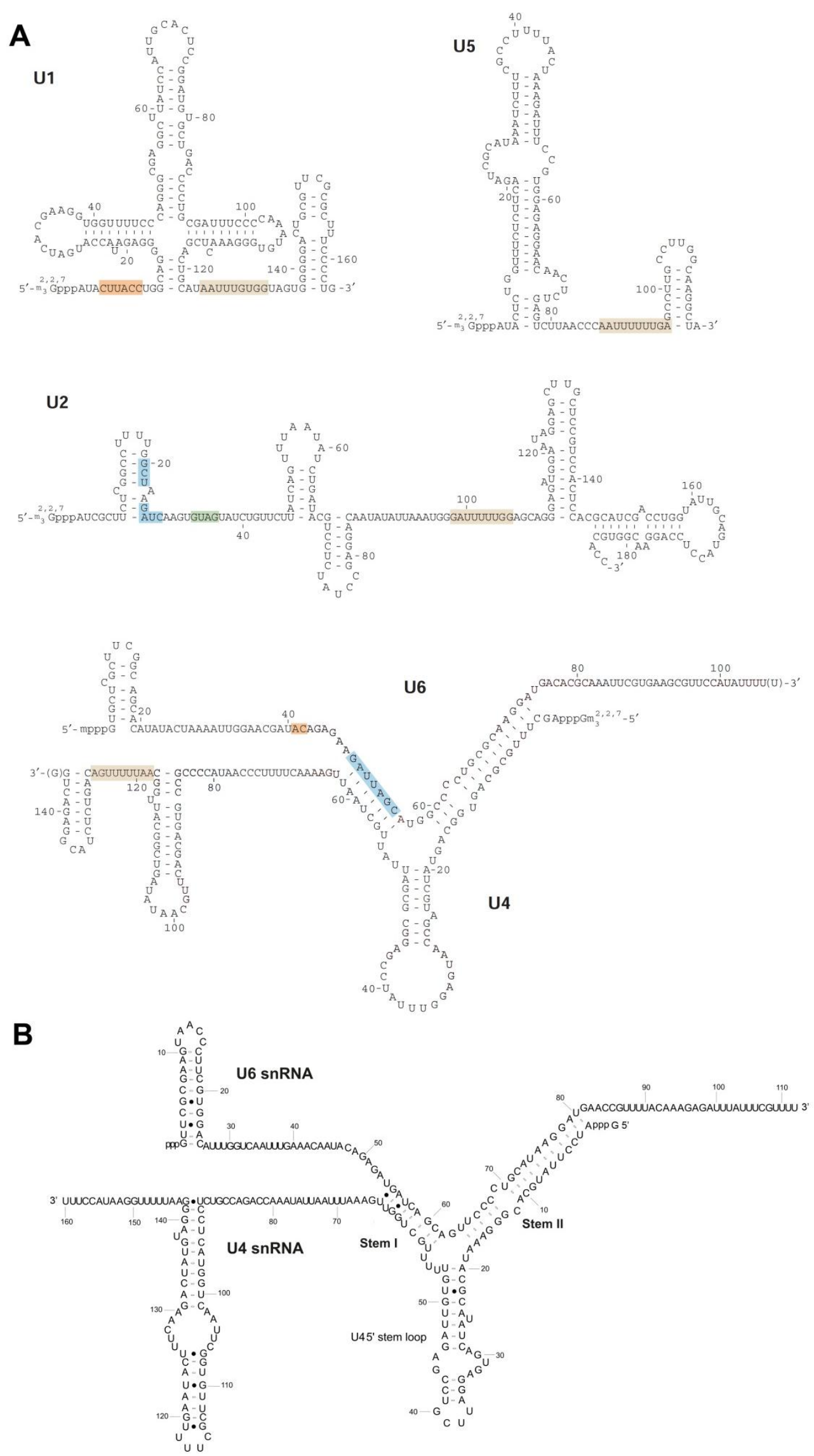

Figure 2.3 Sequences and predicted secondary structures of the human spliceosomal snRNAs and the yeast U4/U6 snRNAs. 
9 Introduction

(Figure legend 2.3) The sequences and secondary structures of the human spliceosomal snRNAs $\mathrm{U} 1, \mathrm{U} 2, \mathrm{U} 4 / \mathrm{U} 6$ and U5 (A) and the yeast U4/U6 (B) are shown. In the case of the human snRNAs), the Sm-interacting sequences are shaded in light yellow and the intermolecular RNA-RNA base pairing sequences are highlighted as follows: interaction sites with the 5 '-splice site, orange; base pairing interactions between $\mathrm{U} 2$ and $\mathrm{U} 6$, blue; interacting region with the branch site, green (Panel A was modified from Patel and Steitz, 2003).

$12 S$

U1

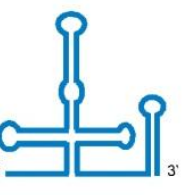

U1 snRNA

\begin{tabular}{|c|}
\hline $\mathrm{Sm}$ \\
\hline $70 \mathrm{~K}$ \\
$\mathrm{~A}$ \\
$\mathrm{C}$
\end{tabular}

$17 S$

U2
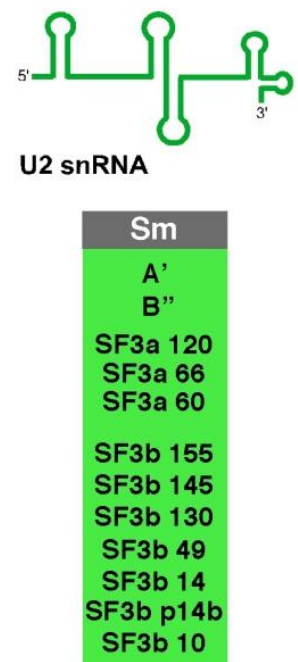

$0.3 \mathrm{MDa}$
0.9 MDa
$20 S$

U5
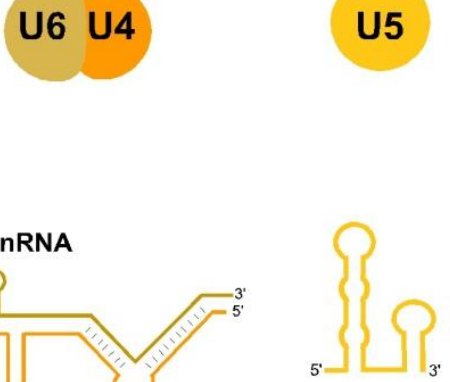

U5 snRNA

\section{Sm/LSm}

hSnu13

hPrp31

20K

hPrp4

hPrp3

U6 snRNA

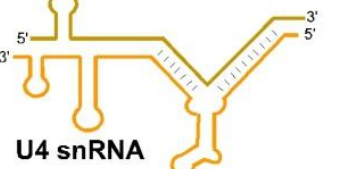

Sm

hPrp8

hBrr2

hSnu114

hPrp6

hPrp28

$52 \mathrm{~K}$

40K
hDib1

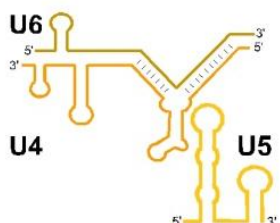

\begin{tabular}{c} 
Sm/LSm \\
hPrp8 \\
hBrr2 \\
hSnu114 \\
hPrp6 \\
hPrp28 \\
40K \\
hDib1 \\
\hline hSnu13 \\
hPrp31 \\
$20 K$ \\
hPrp4 \\
hPrp3 \\
\hline hSad1 \\
$27 K$ \\
hSnu66
\end{tabular}

U5

U6 U4

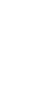

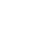




\subsection{Stepwise assembly of the spliceosome}

The splicing cycle entails stepwise assembly and release of the spliceosomal snRNPs on the pre-mRNA (reviewed by Will and Lührmann, 2011 and Wahl et al., 2009). Spliceosome assembly initiates by the binding of the U1 snRNP at the 5'-splice site through base pairing of the U1 snRNA with this region. In contrast to the following steps of spliceosome assembly or its rearrangements, U1 binding is an ATP-independent event (Figure 2.5). The earliest assembly of the spliceosome also involves cooperative recruitment of the SF1/BBP (Splicing Factor1/Branch Binding Protein) and the $\mathrm{U} 2 \mathrm{AF}^{65} / \mathrm{U} 2 \mathrm{AF}^{35}$ (U2 auxiliary factor) heterodimer to the BPS, the polypyrimidine tract and the 3'ss, respectively (Rutz and Séraphin, 1999; Berglund et al., 1997). These series of events lead to formation of the early spliceosomal complex (E complex). Next, the U2 snRNP is engaged in an interaction with the BPS, an event which is promoted by the two RNA helicases Prp5 and Sub2/UAP65, in an ATP-dependent manner (Liao et al., 1992). This base pairing of the U2 snRNA with the BPS, bulges out the branch point adenosine at this region. Furthermore, $\mathrm{U} 2$ binding to the BPS is stabilized by the RS domain of $\mathrm{U}_{2} \mathrm{AF}^{65}$ and by the U2 snRNP associated SF3a/SF3b heteromeric complexes (Hastings and Krainer, 2001; Query et al., 1996; Query et al., 1994). This intermediate complex is termed the pre-spliceosome or A complex. Integration of the pre-assembled U4/U6.U6 tri-snRNP to the A complex, forms the B complex that is still catalytically inactive (also called the pre-catalytic spliceosome). To convert the B complex to a competent spliceosome for catalysis of the first step of splicing, the U1 and the U4 snRNPs must be released and the spliceosome has to undergo major structural rearrangements. The RNA helicases Prp28 and Brr2 are, respectively, involved in the ATP-dependent displacement of the U1 and the U4 snRNPs, which yields the activated $\mathrm{B}$ complex or the $\mathrm{B}^{\text {act }}$ complex. In addition, the EF2 like GTPase Snu114 promotes the U4 release in its GTP-bound state (Small et al., 2006; Staley and Guthrie, 1999; Raghunathan and Guthrie, 1998). At this stage, the Prp2 ATPase remodels the $\mathrm{B}^{\text {act }}$ complex which creates a catalytically active spliceosome or $\mathrm{B}^{*}$ that is capable of catalyzing the first trans-esterification reaction (Warkocki et al., 2009). The resulting complex is called the $\mathrm{C}$ complex, which requires another ATPase, Prp16, to undergo the second step of the splicing. Subsequently, the spliced mRNA is liberated by the action of the Prp22 ATPase (Tseng et al., 2011; Schwer, 2008; Schwer and Meszaros, 2000). The post-spliceosomal complex is disassembled by cooperative action of Prp43 ATPase, Brr2 and Snu114, and the resulting components can be recycled for another round 
of splicing. The released intron-lariat is de-branched by the de-branching enzyme Dbr1 and degraded (Tsai et al, 2005; Danin-Kreiselman, 2003).

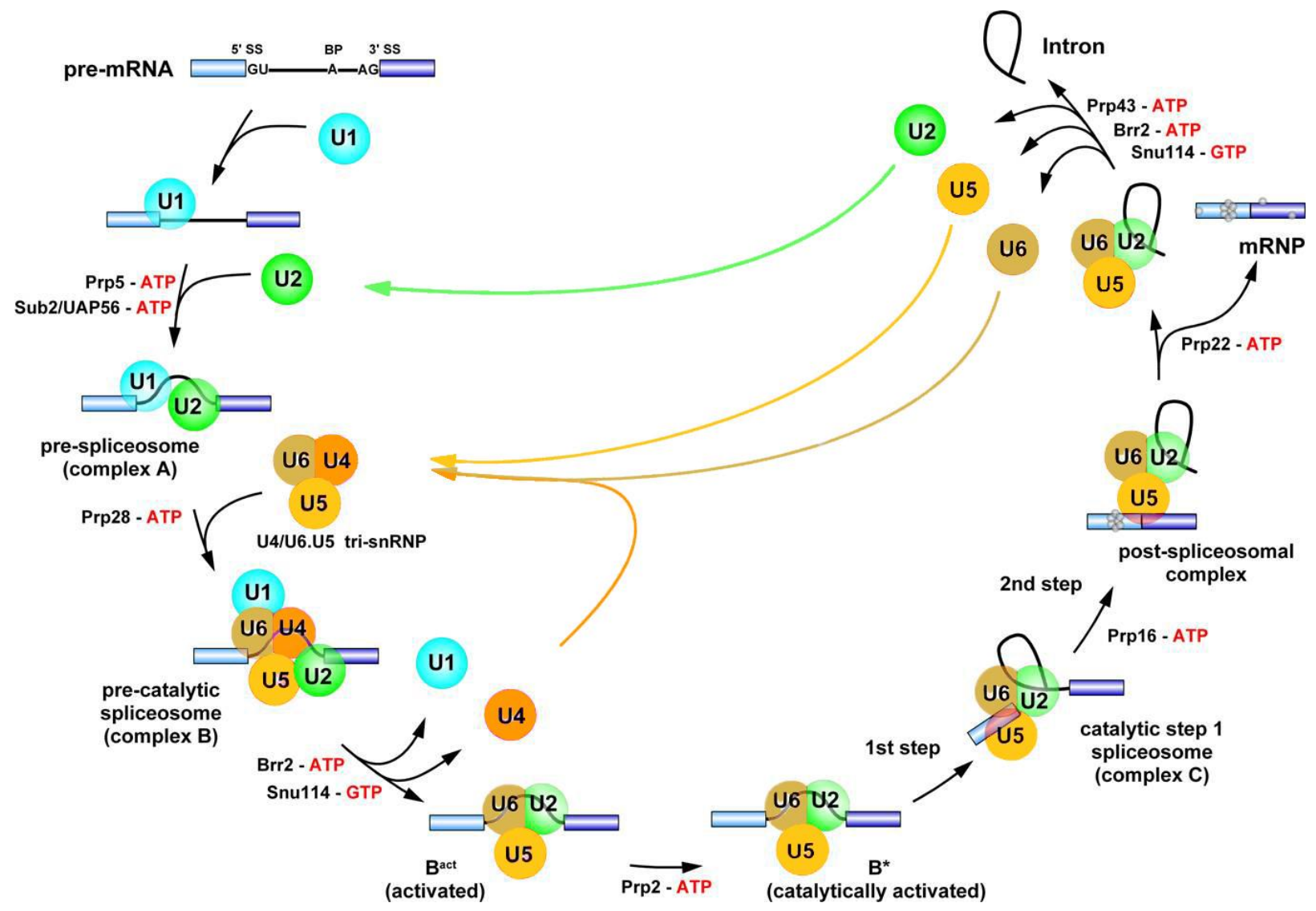

Figure 2.5 Stepwise assembly and disassembly of the major spliceosome.

The splicing cycle shows stepwise assembly and disassembly of the UsnRNPs (colored circles) as major building blocks of the spliceosome. First, the 5'-splice site is recognized by the U1 snRNP followed by ATP-dependent interaction of the U2 snRNP at the branch point sequence. Subsequently, the pre-assembled U4/U6.U5 tri-snRNP is recruited to form the pre-catalytic spliceosome or the B complex. The spliceosome is activated upon release of the U1 and U4 snRNPs followed by further rearrangements leading to formation of the $\mathrm{B}^{*}$ complex that undergoes the first step of splicing. The action of the Prp16 ATPase is required for the second step of splicing to occur by the C complex. Finally, the spliced mRNA is released and the post-spliceosomal complex is disassembled. Eight evolutionary conserved ATPases/helicases that act at specific steps of the splicing cycle, as well as the GTPase Snu114, are indicated (Figure kindly provided by Dr. Berthold Kastner and modified). 
12 Introduction

\subsection{Rearrangements in the spliceosomal RNA-RNA network}

The spliceosome undergoes profound structural rearrangements during the evolution of its active site. These reorganizations can be followed by looking at the network of spliceosomal RNA-RNA interactions, i.e. the snRNA/snRNA and snRNA/pre-mRNA interactions. Moreover, spliceosomal RNA conformational changes can be even more complex and include rearrangements in the secondary and/or tertiary structure of the UsnRNAs (Wahl et al., 2009). This cascade begins by base pairing of the 5'-end of U1 snRNA with the 5'ss. Next, the U2 snRNA base pairs with the BPS, establishing the U2/BPS duplex, in which the branch point adenosine is bulged out which makes its 2'hydroxly group spatially available for nucleophilic attack during the first step of splicing (Figure 2.6). At this stage, the U4/U6.U5 tri-snRNP is recruited to the A-complex (Konforti and Konarska, 1994). Within the tri-snRNP, the U4 and U6 snRNAs are base paired, extensively, forming the stem I and stem II (Figure 2.3 A, B and Figure 2.6) (Mougin et al., 2002). In this conformation, the catalytically important regions of U6 are engaged in base pairing with U4. After integration of the tri-snRNP, the U5 snRNA contacts the 5' and 3' exons, the U1/5'ss and U4/U6 interactions are disrupted during catalytic activation and the invariant ACAGAG-box of the U6 snRNA base pairs with the 5'ss. Furthermore, displacement of the U4 snRNA allows U6 to adopt a catalytically important internal stem loop structure (U6-ISL), and to form additional interactions with U2 through helices Ia and Ib, while its 3'-end was already engaged in base pairing with U2 within the B complex (helix II). The resulting three-dimensional organization of the snRNAs juxtaposes the branched adenosine to the 5'ss of the intron to facilitate the first chemical step of splicing (Burke et al., 2012; Sashital et al., 2004; Ryan and Abelson, 2002; Madhani and Guthrie, 1994). 


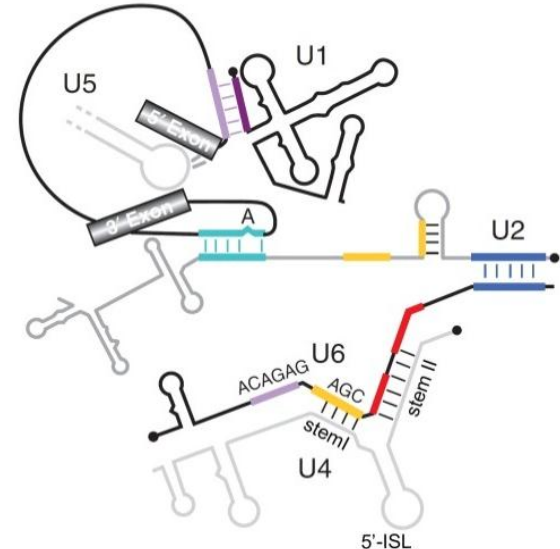

Pre-catalytic spliceosome (B complex)

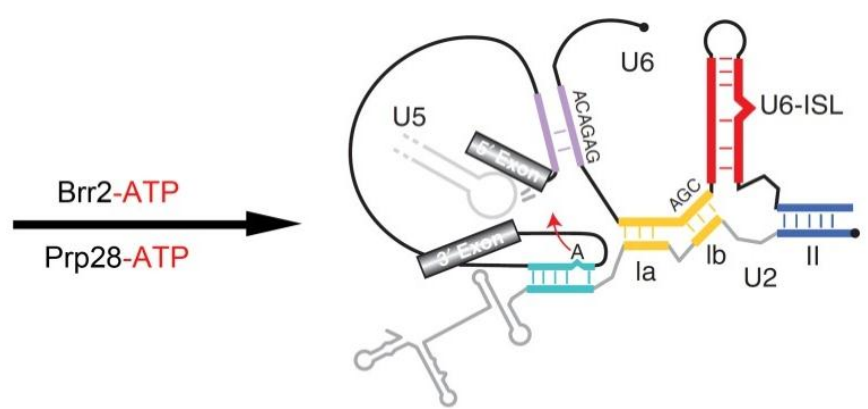

Catalytically activated splicesome (B* complex)

Figure 2.6 Dynamics of the spliceosomal RNA-RNA network.

Schematic representation of the network of snRNA/snRNA and snRNA/pre-mRNA interactions within the pre-catalytic and catalytically activated spliceosome. The catalytically important regions of the snRNAs are colored. The 5'-end of each snRNA is indicated by a black dot. Within the precatalytic splicesome, U4/U6 are base paired through stems I and II, U1 contacts the 5'ss and U2 interacts with the BPS and the 3'-end of U6. Upon the release of the U1 and U4 snRNAs by the action of Prp28 and Brr2, and further rearrangements by the Prp2 ATPase, the catalytically activated spliceosome is formed. These events allow U6 to form additional base pairs with U2 (helices Ia and Ib) and to contact the 5'ss. This intricate network of interactions juxtaposes the branched adenosine to the 5'-exon-intron junction (Figure kindly provided by Dr. Berthold Kastner and modified).

\subsection{RNA helicases as molecular motors of the spliceosome}

RNA helicases are highly conserved enzymes that utilize the free energy of adenosine triphosphate (ATP) binding and hydrolysis to catalyze unwinding of RNA-RNA/RNADNA duplexes that are thermodynamically stable or to remodel ribonucleoprotein complexes (RNPs) by displacing proteins bound to RNAs and aid in formation of proper RNA tertiary structures. RNA helicases are found virtually in all domains of life and are known to play essential roles in various aspects of RNA metabolism. In S. cerevisiae, about $2 \%$ of the protein-encoding genes code for putative RNA helicases or their related proteins (Shiratori et al., 1999). RNA helicases are involved in different RNA metabolic pathways such as RNA splicing, RNA export, ribosome biogenesis, RNA turover, small RNA processing and translation initiation, termination and inhibition events (Bleichert and 
Baserga, 2007; Tanner and Linder, 2001). Given their wide functionalities, RNA helicases have acquired significant attention over the past years and interesting models have been proposed to link the structures and functional mechanisms of these enzymes.

Helicases have been primarily classified based on their conserved sequence motifs into five superfamilies, SF1 to SF5. SF1 and SF2 are the two largest groups that share eight conserved sequence motifs I, Ia, Ib, II, III, IV, V, VI (Table 2.1, Figure 2.7). Variation in the consensus sequence of the motifs is the basis for classification within each superfamily. Most of RNA helicases belong to the SF2 superfamily that includes proteins of DEAD, DEAH and Ski2-like (DExH) subfamilies, generally known as DExD/H-box proteins named according to their consensus sequence of motif II (DExx). Thus, each family based on this type of segregation may include helicases with different phylogenetic source, substrate specificity and/or mechanistic features, such as directionality of unwinding (Figure 2.8; Bleichert and Baserga, 2007; Caruthers and McKay, 2002).

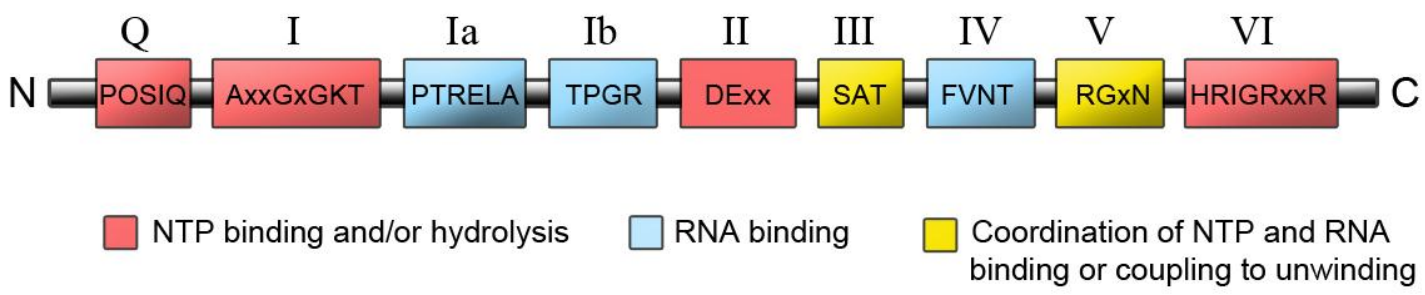

Figure 2.7 Diagram of conserved sequence motifs of DEAD-box RNA helicases and their functions.

The Q-motif is specific to the DEAD-box helicases and acts as ATP sensor. The corresponding function of each motif has been color coded and is shown at the bottom.

\subsection{Characteristics of the conserved RNA helicase motifs}

Crystal structures of SF1 and SF2 helicases have shown that the invariant helicase motifs form a functional entity whereby they cooperate together to bind ATP and nucleic acid substrates. These observations have been complemented by extensive functional studies of the individual motifs to unravel their roles in the molecular mechanism of helicases. Among the eight canonical helicase motifs, motifs I and II (also named Walker A and Walker B, respectively) show the highest degree of conservation in SF1 and SF2 helicases 
and are found in NTP hydrolyzing enzymes. Both are identified as GK(T/S) and DExD/H consensus sequences. Motif I forms a pocket in which the amino group of the lysine interacts with the phosphates of NTP/NDP and the threonine residue coordinates $\mathrm{Mg}^{2+}$. Within the motif II, the aspartate residue coordinates $\mathrm{Mg}^{2+}$ ion and the glutamate residue has been proposed to activate the attacking water molecule that promotes NTP hydrolysis (Figure 2.9). Motifs Ia, Ib, IV and V show RNA substrate binding and motif III couples ATP hydrolysis to unwinding activity. Motif VI has been suggested to play role in RNAcoupled ATP hydrolysis (Linder and Daugeron, 2000; Gorbalenya and Koonin, 1993). An additional motif called the Q-motif has been recently identified upstream of motif I. It is comprised of a conserved glutamine residue and is thought to be a specific characteristic of the DEAD-box helicases. The Q-motif acts as an ATP sensor and thereby regulates ATP binding and hydrolysis (Cordin et al., 2004; Tanner et al., 2003).

\subsection{Mechanisms of nucleic acid strand separation by helicases}

The ultimate goal of the various core domains of an RNA helicase is to efficiently couple the energy of ATP hydrolysis to base pair opening and/or translocation along an RNA substrate. However, some helicases are comprised of flanking domains that are not involved in the mechanism of helicase activity and may be necessary to integrate their activity into the function of a larger molecular machinery. Most of our knowledge about the functional mechanism of helicases has been obtained by structure-function analyses of DNA helicases. However, these mechanisms can be, in principle, also employed by RNA helicases (Bleichert and Baserga, 2007).

Helicases often require a single-stranded nucleic acid stretch to bind and initiate their remodeling cycles. After binding they show a bias in the polarity of translocation along the bound strand (loading strand) i.e. in 3' to 5' or 5' to 3' direction. For example, NPH-II and NS3 RNA helicases have been demonstrated to be merely dependent on a covalently linked RNA backbone and show no affinity for nucleotide bases. In addition, some helicases have specificity for the nature of the loading strand and in certain cases they are also sensitive to the type of the displaced strand. In a variety of biological processes, helicases need to separate long base pairs of nucleic acids which call for a stepwise catalysis of unwinding. In such cases, the helicase needs to stay on its path by repeated 
16 Introduction

Table 2.1 Examples of SF1 and SF2 RNA helicase subfamilies from S.cerevisiae

\begin{tabular}{|c|c|c|c|c|}
\hline \multirow{2}{*}{$\begin{array}{l}\text { Superfamily } \\
\text { Subfamily }\end{array}$} & \multicolumn{3}{|c|}{ SF2 } & \multirow{2}{*}{$\begin{array}{c}\text { SF1 } \\
\text { UPf1-like }\end{array}$} \\
\hline & DEAD & DEAH & Ski2-like & \\
\hline mRNA splicing & Sub2, Prp5, Prp28, Ded1 & $\begin{array}{l}\text { Prp2, Prp16, } \\
\text { Prp22, Prp43 }\end{array}$ & Brr2 & \\
\hline RNA export & Sub2, Dbp5 & & & \\
\hline $\begin{array}{l}\text { RNA turnover and } \\
\text { quality control }\end{array}$ & Dhh1, Dbp2 & & Ski2, Mtr4 & Upf1 \\
\hline Ribosome biogenesis & Has1, Dbp2-4, Dpb6-10 & Prp43 & Mtr4 & Sen1 \\
\hline Translation initiation & eIF4A, Ded1, Dbp1 & & & \\
\hline Translation termination & Dbp5 & & & Upf1, Hel1 \\
\hline Translation inhibition & Dhh1 & & Ski2, Slh1 & \\
\hline Small RNA processing & & & Mtr4 & Sen 1 \\
\hline $\begin{array}{l}\text { Mitochondrial RNA } \\
\text { metabolism }\end{array}$ & Mss116, Mrh4 & & Suv3 & \\
\hline
\end{tabular}

(Adapted from Bleichert and Baserga, 2007)

catalytic cycles to open several base pairs continuously. A number of mechanisms have been proposed for translocation and nucleic acid unwinding by helicases, all of which involve NTP hydrolysis, alteration of nucleic acid binding affinity and a subsequent conformational change (power stroke) that leads to translocation and/or strand separation (Tanner and Linder, 2001). 

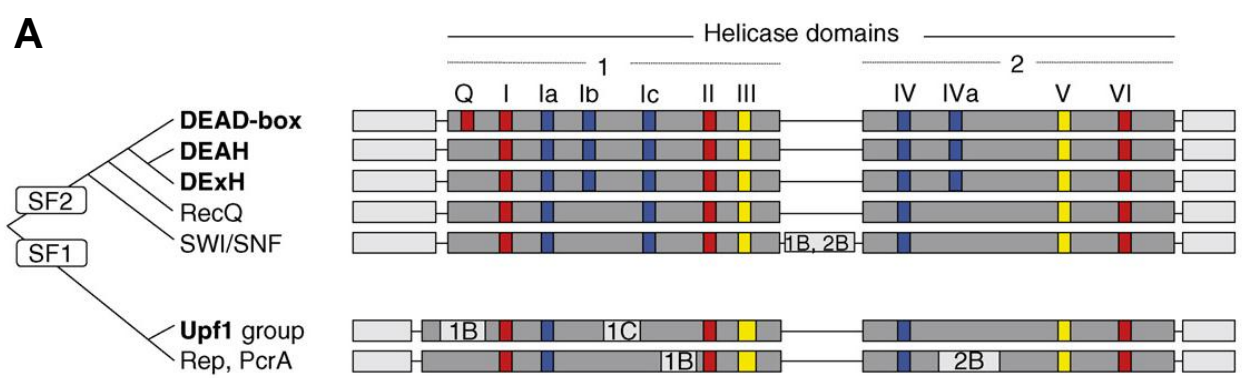

B
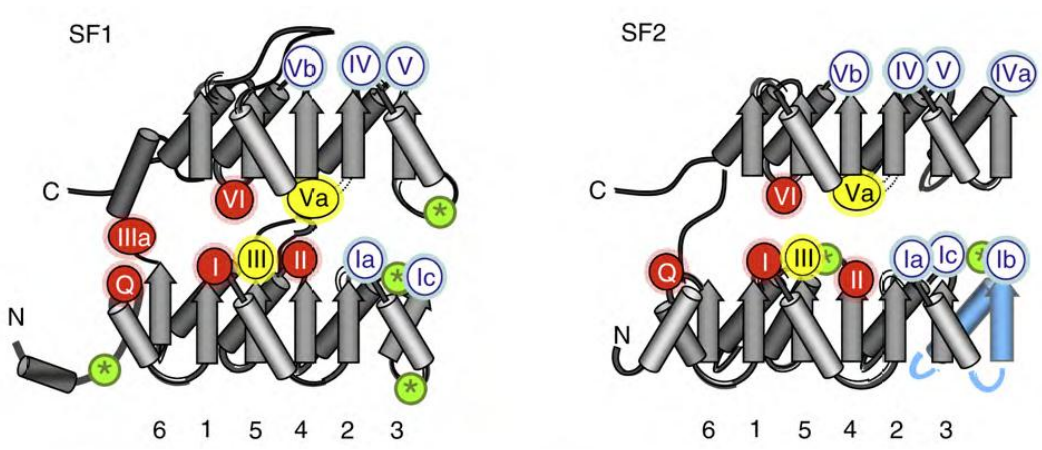

Figure 2.8 Sequence and structural organization of the conserved motifs of RNA helicases.

(A) Conserved helicase motifs of different SF1 and SF2 helicase families (indicated at the left; RNA helicase families are in bold). (B) Topology of the two RecA-like domains of SF1 and SF2 RNA helicases. The helicase motifs are indicated and are colored as in figure 2.7. Numbers below the diagram indicate the connectivity of the $\beta$-strands of the RecA1 domain. Domain insertions are shown by green circles (Panel A is adapted from Jankowsky and Fairman, 2007; Panel B is adapted from Jankowsky, 2011).

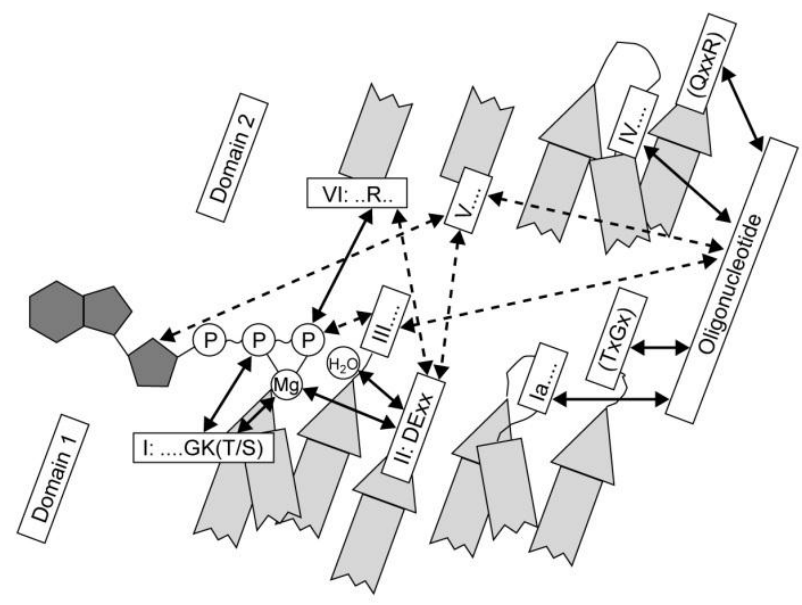

Figure 2.9 Interactions of conserved motifs of SF1 and SF2 helicases with ATP and nucleic acid substrates.

Solid arrows indicate contacts that are observed in both SF1 and SF2 helicases. Dashed arrows indicated interactions that maybe specific to a particular helicase family. For detailed description of the interactions refer to the main text (Adapted from Caruthers and McKay, 2002). 
18 Introduction

\subsubsection{Stepping models}

The stepping models require two RNA binding sites that in response to the signals transduced from the NTPase active center undergo intermittent binding and release cycles on the RNA. These dual binding sites can act independently of one another and thereby one site can always anchor the helicase to RNA. One type of stepping model is the socalled inchworm mechanism, whereby a cycle of nucleic acid binding, release and translocation starts with one binding site bound to the nucleic acid strand tightly, while the other site is weakly bound. The weak site dissociates, moves forward to a new position on the nucleic acid, and forms tight interactions at this position. At this stage, the former tight binding site has been weakened, and the helicase moves towards the first binding site. Thus, one cycle of inchworm motion is completed upon six sequential conformational changes. This mechanism is applicable to monomeric and dimeric helicases. (Patel and Donmez, 2006; Velankar et al., 1999).

\subsubsection{Brownian motor model}

In contrast to the stepping models, the Brownian motor mechanism involves only one nucleic acid binding site (Figure 2.10). Biochemical and structural investigations have identified two distinct conformational states of helicases based on the state of their bound NTP, namely a tight and a weak binding state. Upon binding or hydrolysis of NTP, the helicase can switch between these states. In the tight binding state, the helicase cannot move on the loading strand and it needs a transition to the weak binding state to be able to start repositioning in either direction (Brownian motion) or to dissociate from the substrate. When the helicase regains its tight binding conformation, it may step forward along the nucleic acid with a power stroke. Those helicases that have fluctuated in the opposite direction restore their initial binding sites. Thus, compared to the inchworm mechanism, in this model ATP hydrolysis is not tightly coupled to translocation and several ATP molecules may be hydrolyzed prior to one-step movement of the helicase ( $\mathrm{Rad}$ and Kowalczykowski, 2012; Patel and Donmez, 2006; Delagoutte and Hippel, 2002). 

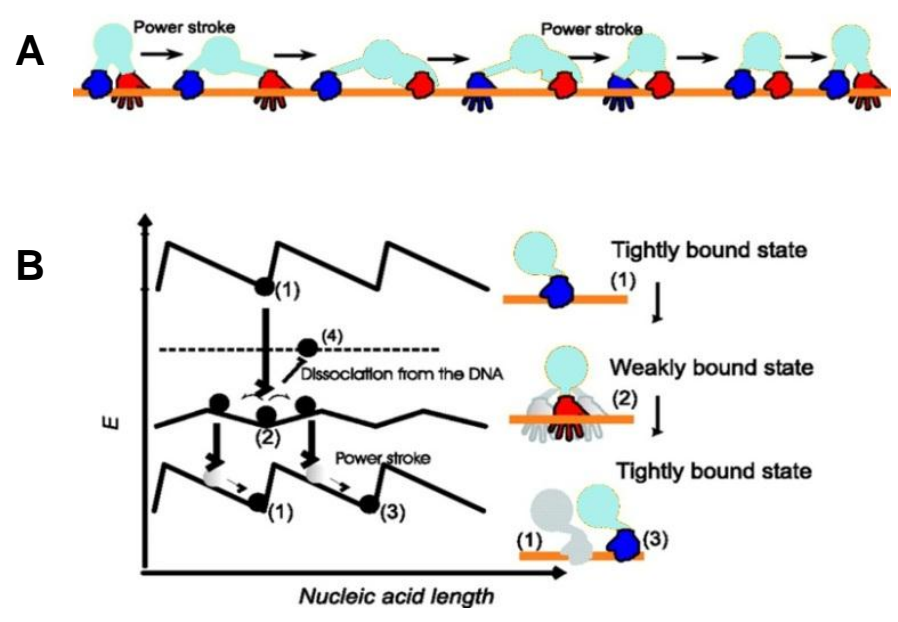

Figure 2.10 Proposed models of helicase translocation.

(A) Inchworm mechanism. A cycle of inchworm movement (power stroke) of a helicase is shown that is comprised of six conformational changes. The two nucleic acid binding sites of the helicase undergo changes in the affinity for nucleic acid that leads to transition from tight (closed hand) to week (open hand) binding or vice versa. (B) Brownian motor model. On the right, the helicase monomer undergoes changes in its affinity for nucleic acid from a tight to weak binding state. In the weakly bound state, the helicase starts fluctuating (2). Thereby some molecules move forward and a fraction move to the opposite direction until they restore their tightly bound state ( 1 or 3 ). On the left, changes in the free energy state of the helicase-nucleic acid complexes along the nucleic acid are shown. (Modified from Patel et al., 2006).

\subsubsection{Local strand separation by DEAD-box RNA helicases}

All the above mentioned mechanisms can be only applied to processive helicases but only a few RNA helicases have been demonstrated to show appreciable processivity in vitro. Recent studies have evidenced that there are RNA helicases that appear to locally displace RNA-RNA or RNA-protein interactions without translocation along the loading strand (Figure 2.11). Indeed, biochemical and structural studies demonstrate a different mechanism for the action of this group of RNA helicases. Cooperative binding of ATP and RNA to these helicases induces a transition from open to closed conformation that can lead to a bend in the RNA duplexes. Subsequently, ATP hydrolysis may destabilize the closed conformation and recycles the RNA helicase (Liu et al., 2008; Yang et al., 2007; Sengoku et al., 2006). This model explains how DEAD-box RNA helicases can remodel their substrates without the requirement for a loading strand such as displacement of blunt RNA duplexes, and in principle, how a nucleic acid duplex can be unwound by non-translocating helicases (Henn A et al., 2012; Mallam et al., 2012; Russell et al., 2012). 


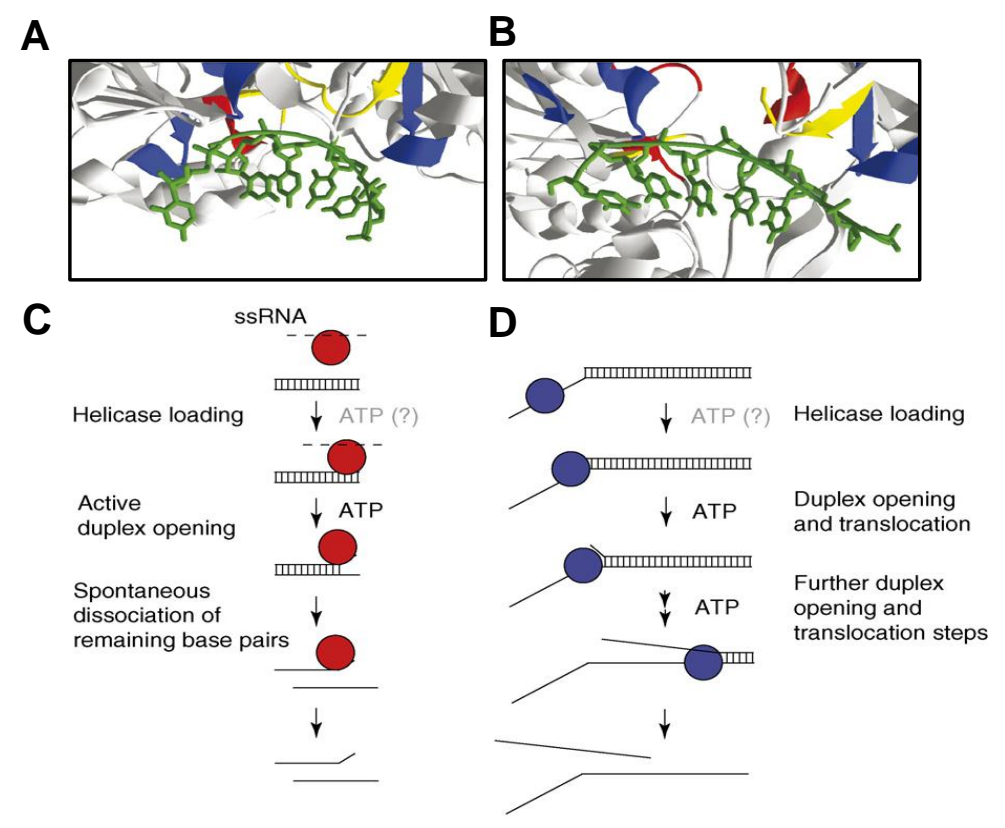

Figure 2.11 Two distinct modes of RNA duplex unwinding by processive (DExH-box) and non-processive (DEAD-box) RNA helicases.

Close-up views of the nucleic acid bound to the DEAD-box RNA helicase, Vasa (A) or to the DExH-box helicase, HCV NS3 (B) are shown with the conserved helicase motifs colored as in figure 2.7. General modes of local RNA strand separation by a DEAD-box RNA helicase (C) and processive unwinding by a DExH-box helicase (D) (Adapted from Jankowsky and Fairman, 2007).

\subsection{Regulation of RNA helicase activity by effector proteins}

Most of the RNA helicases function in the context of larger RNP complexes such as the spliceosome or the exon-junction complex (EJC), where they interact with other proteins and their activity is required at a particular step of the biological process mediated by these complexes. Moreover, RNA helicases often exhibit high specificity for their substrates and/or functional efficacy in vivo, whereas in many cases their biochemical function is non-specific and very poor in isolation. Thus, an important question is how the functional specificity of the numerous RNA helicases is maintained for specific cellular processes, despite them sharing conserved helicase domains. Indeed, many RNA helicases harbor specific associated domains, flanking their helicase core, which determine their specificity and/or modulate their functionality e.g. by serving as interaction sites with effector proteins. Effector proteins or cofactor proteins can stimulate or inhibit helicase and/or ATPase activities of RNA helicases in different ways. When the helicase is a component of 
a multi-protein complex, an effector protein may recruit the helicase to the complex. Some cofactor proteins can cooperatively enhance the specificity and/or helicase activity of RNA helicases by bridging the RNA substrate. Furthermore, these regulatory proteins can mediate direct physical interaction with the RNA helicase, by stabilizing a particular conformation that is either favorable (stimulatory) or inhibitory for its ATPase/helicase activities (Bleichert and Baserga, 2007; Cordin et al., 2006; Silverman et al., 2003). The processivity of a helicase is defined as the probability that the enzyme will translocate forward and conduct the next step of base pair opening as opposed to dissociating from its RNA substrate. Helicase processivity is often regulated by cofactor proteins that may interact functionally with the helicase to trap intermediate single-stranded RNA products of the double-stranded RNA unwinding reaction and facilitate their subsequent use (von Hippel and Delagoutte, 2001).

To date, many RNA helicase associated proteins have been identified and proposed to act as potential helicase cofactors; however, the effects of only very few of them on their corresponding RNA helicase have been biochemically investigated. eIF4A is one of the few well-characterized eukaryotic RNA helicases. eIF4A interacts with eIF4G and eIF4E, forming the eIF4F complex that is required for cap-dependent translation initiation. Purified eIF4A exhibits RNA-stimulated ATPase activity and nonprocessive RNA unwinding activity. Strikingly, eIF4G directly interacts with this helicase and stimulates its ATPase activity in vitro (Bleichert and Baserga, 2007;Korneeva et al., 2005). Furthermore, eIF4B is another effector protein that binds eIF4A alone or in complex with eIF4F and enhances the coupling of ATP hydrolysis to strand separation by eIF4A (Özeş et al., 2011).

Dbp5 is a DEAD-box RNA helicase that acts in mRNA export from the nucleus, and it is thought to remodel the mRNPs at the nuclear pore complex. Dbp5 directly binds to its cofactor protein Gle1, which leads to stimulation of its ATPase activity. Interestingly, inositol hexakisphosphate ( $\operatorname{InsP}_{6}$ ), a small second messenger molecule that interacts with Gle1, is necessary for the optimal activation of Dbp5 by Gle1 (Alcázar-Román et al., 2006). Very recently, the crystal structure of Dbp5-Gle1- $\mathrm{InsP}_{6}$ and biochemical studies on this complex, provided a mechanistic insight into the regulatory mechanism of Dbp5 by its cofactors. Montpetit et al., demonstrated that both Gle1-InsP ${ }_{6}$ and eIF4G helicase cofactors activate their interacting DEAD-box helicases by stimulating RNA release and thus, fast ATP-dependent recycling of enzymes that have just unwound RNA duplexes (Montpetit at al., 2011). An example of regulation of a processive RNA helicase by an effector domain, 
is the stimulation of the helicase cassette of hepatitis $\mathrm{C}$ viral nonstructural protein 3 (NS3) by its associated domain. The full-length NS3 protein consists of an N-terminal serine protease domain and a C-terminal helicase/ATPase cassette. Intriguingly, the protease domain is required for optimal RNA unwinding activity of the NS3 helicase cassette and strongly increases the affinity of NS3 for RNA (Beran et al., 2007; reviewed in Frick, 2007).

The effector proteins not only activate RNA helicases, but they can also specifically suppress these enzymes. However, our current knowledge of this type of regulatory mechanism is very poor. Regulation of the mammalian eIF4AIII RNA helicase, which is a core component of the exon-junction complex (EJC), is one of those very few examples. Here, the MAGOH/Y14 heterodimer within the EJC, interacts with eIF4AIII and inhibits the release of inorganic phosphate and ADP (ATP turnover), and thereby locks eIF4AIII and the EJC onto the mRNA. This is achieved through locking a closed conformation of eIF4AIII, in which the hydrolyzed ATP and the bound RNA are trapped (Nielsen et al., 2009; Andersen et al., 2006).

\subsection{Spliceosome activation: Brr2 as a key player}

During pre-mRNA splicing, after completion of the spliceosome assembly, the major step is the exchange of the ACAGAG-box of U6 snRNA for U1 snRNA at the 5'-splice site, and unwinding of the most stable duplex of the spliceosome, formed through extensive intermolecular base pairing (stem I and stem II) of U4 and U6 snRNAs (Brow and Guthrie, 1988). The displacement of U4/U6 snRNA interaction is a central event during catalytic activation that makes U6 free to adopt catalytically important structures (e.g. U6 internal stem loop), and to establish new interactions with the U2 snRNA (helix Ia and Ib) (refer to Figure 2.6; Brow et al., 2002). The DExH-box protein Brr2 (h200K), has been implicated in the ATP-dependent unwinding process of U4/U6 snRNAs (Kim and Rossi, 1999; Raghunathan and Guthrie, 1998; Laggerbauer et al., 1998). Brr2 is an integral component of the U5 snRNP and joins the pre-spliceosome (A complex) as a component of the U4/U6.U5 tri-snRNP (Wahl et al., 2009; Laggerbauer et al., 1996; Lauber et al., 1996). In contrast to most of the spliceosomal ATPases/helicases that are recruited to the spliceosome transiently, Brr2 remains stably associated with the spliceosome, and is thought to act not only as a key player during the activation step, but also as a facilitator of 
U2/U6 dissociation during disassembly of the spliceosome (Small et al., 2006). Furthermore, Brr2-mediated activation of the spliceosome results in the dissociation of a number of U4/U6-specific proteins.

Brr2 is the unique representative of the Ski2-like subfamily of the SF2 RNA helicases (see Table 1), and the largest helicase (ca. $245 \mathrm{kDa}$ ) in the spliceosome which contains an $\mathrm{N}$ terminal region (ca. 400 amino acids) followed by two tandem helicase domains (Raghunathan and Guthrie, 1998). Each helicase cassette is composed of conserved dualRecA domains, typical of helicases, followed by a functionally unknown region which shows homology to a portion of the Sec63p subunit of the ER translocon (Ponting, 2000). The Sec63 unit may confer Brr2 functional properties that could be specific to this spliceosomal helicase. Previous yeast genetic studies have shown that only the activity of the N-terminal helicase cassette of Brr2 is required for pre-mRNA splicing and cell viability. The C-terminal cassette of Brr2 bears catalytically detrimental mutations within the helicase motifs and is thought to be inactive (Kim and Rossi, 1999). Furthermore, exhaustive two-hybrid screening with Brr2 has identified a number of proteins, essential for different steps of splicing, to interact with the C-terminal cassette of Brr2; e.g. Prp2 and Prp16 (Liu et al., 2006; van Nues and Beggs, 2001). Therefore, the second cassette of Brr2 is generally considered as a versatile protein-protein interaction platform.

Since, Brr2 is a core component of the spliceosome that initiates a cascade of structural and compositional rearrangements; it must be faithfully regulated to prevent premature activation of the spliceosome. Furthermore, as it is required twice during the splicing cycle, it needs to be repeatedly switched on and off. Within the U5 snRNP, Brr2 stably interacts with two large spliceosomal proteins, Prp8 and Snu114 (Achsel et al., 1998), both of which have been implicated in the regulation of Brr2.

Prp8 (human 220K) is the largest and highly conserved scaffolding protein of the spliceosome that constitutes part of the catalytic core of the spliceosome, and is involved in several central molecular rearrangements that takes place (reviewed in Grainger and Beggs, 2005). The evidence for the role of Prp8 in spliceosome activation was provided by a genetic mutation in U4 snRNA (U4 cs-1) that hyperstabilizes the extended U4/U6 stem I and prevents the U6 interaction with the 5'-splice site. Indeed, previous genetic studies proposed that Prp8 may regulate the exchange of U6 for U1 at the 5'-splice site. The U4 cs-1 mutation was shown to stall the U1and U4/U6 dissociation steps. Importantly, several mutations in Prp8 could suppress the U4 cs-1 phenotype. This led to the proposal that Prp8 
may negatively regulate Brr2 activity (Kuhn and Brow 2000; Kuhn et al. 1999; 2002). In addition, previous two-hybrid data found the interaction of the C-terminal region of Prp8 with Brr2 (Liu et al., 2006; van Nues and Beggs, 2001). This region contains a domain with a three-dimensional fold resembling RNase $\mathrm{H}$, flanked on one side by a $\beta$-hairpin loop and on the other by an $\alpha$ helical domain (Pena et al. 2008; Ritchie et al. 2008; Yang et al. 2008). Previously, in the human B complex, a cross-link was identified between the 5 'ss and the Prp8 RNase H domain (Reyes et al. 1996; Reyes et al. 1999), leading to the proposal that it may be involved in the handover of the 5'ss from the U1 snRNA to the ACAGAG-box of the U6 snRNA. The RNase $\mathrm{H}$ domain of Prp8 is followed by a Jab1/MPN-like domain and a C-terminal region, which is partly unstructured, and is linked to a human retinal degenerative disease, retinitis pigmentosa (Maeder et al., 2009, Pena et al, 2007). The Jab1 domain shows similarity to $\mathrm{Zn}^{2+}$-dependent isopeptidases, but it has lost its deubiquitination activity, while retained its ability to bind ubiquitin (Bellare et al. 2006).

Snu114 (human 116K) is the homologous of the eukaryotic elongation factor 2 (EF-2), a GTPase that promotes the translocation of mRNA and tRNA through the ribosome (Fabrizio et al., 1997). Mutations in Snu114 lead to formation of the arrested spliceosome, where U4/U6 is accumulated, and suggest a role for this protein in the regulation of U4/U6 unwinding (Bartels et al., 2002). Moreover, Snu114 is involved again during the disassembly of the spliceosome, where it regulates the release of U2 and U6 snRNAs. Indeed, it has been suggested that the GTP-bound state of Snu114 promotes both spliceosome activation and disassembly through regulation of Brr2 activity (Small et al., 2006).

\subsection{Impaired function of Brr2 leads to human retinal disease}

Retinitis pigmentosa is a hereditary disorder causing progressive degeneration of the photoreceptors in the retina. It leads to night blindness in patients, and upon further progression at later ages, complete loss of visual fields. Unlike mutations in genes that have specific functions in the retina, those in the splicing-related genes, $\operatorname{prp} 8, \operatorname{brr} 2, \operatorname{prp} 3$ and prp31, are ubiquitously expressed in all tissues, and cause an autosomal dominant form of retinitis pigmentosa (Ivings et al., 2008). Importantly, these mutant splicing factors are components of the U4/U6.U5 tri-snRNP, which indicates a potential defect in the 
25 Introduction

formation of functional tri-snRNP. Recently, it has been reported that retinal cells contain a high level of snRNPs and spliced pre-mRNAs, indicating an enhanced splicing activity in these cells. Thus, unlike other tissues, retinal cells appear to be more sensitive to splicingrelated defects (Tanackovic et al., 2011).

A number of missense or nonsense mutations in the C-terminal tail of the Prp8 Jab1 domain lead to a severe type of retinitis pigmentosa (RP13) (Towns et al., 2010; MartínezGimeno et al., 2003). In addition, several missense mutations have recently been identified within the helicase domains of the N-terminal cassette of Brr2 that give rise to early-onset retinal degeneration (RP33; Liu et al., 2012; Benaglio et al., 2011). Together, these naturally occurring mutations may indicate fundamental defects in the mechanisms underlying the Brr2-mediated activation of the spliceosome. 


\section{Discussion}

The DExH-box RNA helicase Brr2 has been implicated in the activation process of the spliceosome. It contains two tandem helicase cassettes, each encompassing canonical dual RecA domains, flanked by a Sec63 homology unit of unknown function. In this work, published in Mol. Cell (2009), it was found that the crystal structure of the C-terminal Sec63 unit of Brr2 shows previously unknown structural similarity to an archaeal DNA helicase Hel308. This similarity allowed to devise a model of the N-terminal helicase cassette of Brr2, which was further validated by rational mutagenesis combined with in vivo analysis and in vitro enzymatic approaches. These findings showed how the RecAlike domains and the Sec63 unit form a functional entity suitable for RNA duplex unwinding (further discussed in sections 3.1 and 3.2). The crystal structure of a large fragment of human Brr2, encompassing both helicase cassettes, solved by our collaborators, could provide a basis for further functional analyses. This work showed that the C-terminal helicase cassette of $\mathrm{Brr} 2\left(\mathrm{Brr}^{\mathrm{CC}}\right)$ is required as an intramolecular cofactor for the active $\mathrm{N}$-terminal cassette $\left(\mathrm{Brr}^{\mathrm{NC}}\right)$. This finding was further corroborated by structure-guided mutagenesis along the extensive interaction surface of the helicase cassettes. It is also shown that $\mathrm{Brr}^{\mathrm{CC}}$ binds but cannot hydrolyze ATP and that mutations that disrupt its nucleotide-binding pocket strongly affect helicase activity of the enzyme. Together, the results were published in PNAS (2012) and are discussed in sections 3.3, 3.4 and 3.5. Next, I examined the path and the direct targeting region of Brr2 on U4/U6 snRNAs and show that Brr2 is loaded onto the central domain of U4 preceding U4/U6 stem I, and thus translocates in a $3^{\prime}$ to $5^{\prime}$ 'direction along U4 to unwind the U4/U6 stem I first. Furthermore, I investigated the regulation of Brr2 by a C-terminal region of Prp8, a large and highly conserved multi-domain protein of the spliceosome. This region contains consecutive RNase $\mathrm{H}$ and Jab1/MPN-like domains. I found that the RNase H domain of Prp8 binds the U4/U6 snRNAs with the U4 central domain contributing to complex formation. I also identified amino acids of the Prp8 RNase $\mathrm{H}$ domain involved in RNAprotein interactions and demonstrated that the RNase $\mathrm{H}$ domain inhibits Brr2-catalyzed U4/U6 unwinding by sequestering the loading RNA strand, U4 snRNA. This part was recently published in Genes Dev. (2012) and is discussed here in sections 3.6, 3.7, 3.8 and 3.9. In addition, biochemical assays, combined with the crystal structure of human Brr2 complexed with the Jab1/MPN domain of Prp8, showed that the Jab1 domain binds Brr ${ }^{\mathrm{NC}}$, and that the C-terminal tail of Prp8 Jab1, can inhibit Brr2-mediated U4/U6 snRNA 
unwinding by transiently occluding Brr2's RNA binding channel. Upon removal of this tail from the Brr2's RNA pocket, Jab1 acts as a coactivator, enhancing the efficiency with which Brr2 couples ATP hydrolysis to U4/U6 strand separation and enabling Brr2 to act processively. Finally, in vitro and in vivo characterization of Prp8 Jab1 mutations leading to retinitis pigmentosa in human indicates that subtle changes in the Prp8Jab1/MPN Cterminal tail can alter regulation of Brr2 activity. Thus, these studies (submitted for publication; further discussed in sections $3.10,3.11$ and 3.12) reveal a unique dual regulatory mechanism of the Prp8 Jab1 domain in regulation of the Ski2-like helicase Brr2, and provide novel insights into the intricate cascade of spliceosome activation.

\subsection{An initial structure-based working model of Brr2 RNA helicase}

The crystal structure of Brr2's C-terminal Sec63 unit (C-Sec63), solved by Vlad Pena, revealed a previously unknown similarity of two domains, a helical-bundle (HB) domain and a helix-loop-helix (HLH) domain to the domains IV and V of the archaeal DNA helicase Hel308 (Mol. Cell, 2009). However, the C-terminal Immunoglobulin-like (IG) domain was absent in the structure of Hel308. This outlines the same architectural organization of domains in Brr2 helicase cassettes as in Hel308 (Figure 3.1A). Furthermore, this structural homology together with sequence similarity of the RecA-like 1 (RecA1) and RecA2 domains allowed building a homology model of the Brr2 N and Cterminal cassettes using the Hel308 structure as a template.

Hel308 is a processive Ski2-like DNA helicase with 3' to 5' directionality that functions at the stalled replication forks (Guy and Bolt, 2005). The recent crystal structure of archaeal Hel308 in complex with a short DNA duplex containing a single-stranded 3'-overhang (Büttner et al., 2007) provided an insight to the mechanism of nucleic acid strand separation by the family of Ski2-like helicases, to which Brr2 also belongs (Figure 3.1B and 1C). In this DNA-helicase complex, the single-stranded region of DNA is threaded through the central tunnel formed by the RecA1, RecA2 and the HB domains and subsequently, it bends around the HB domain and contacts the HLH domain via the sugarphosphate backbone. Indeed, most of helicases are dependent on the presence of a singlestranded overhang adjacent to the duplex junction to initiate unwinding (loading strand). However, the modes of interactions with the loading strand can be specific and vary according to the unwinding mechanism of helicases (Mackintosh and Raney, 2006). In this 
A
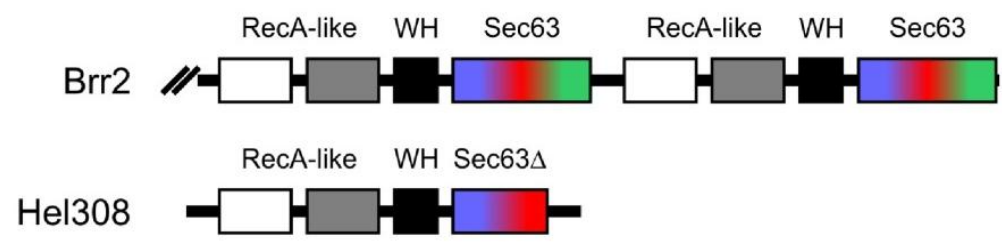

B
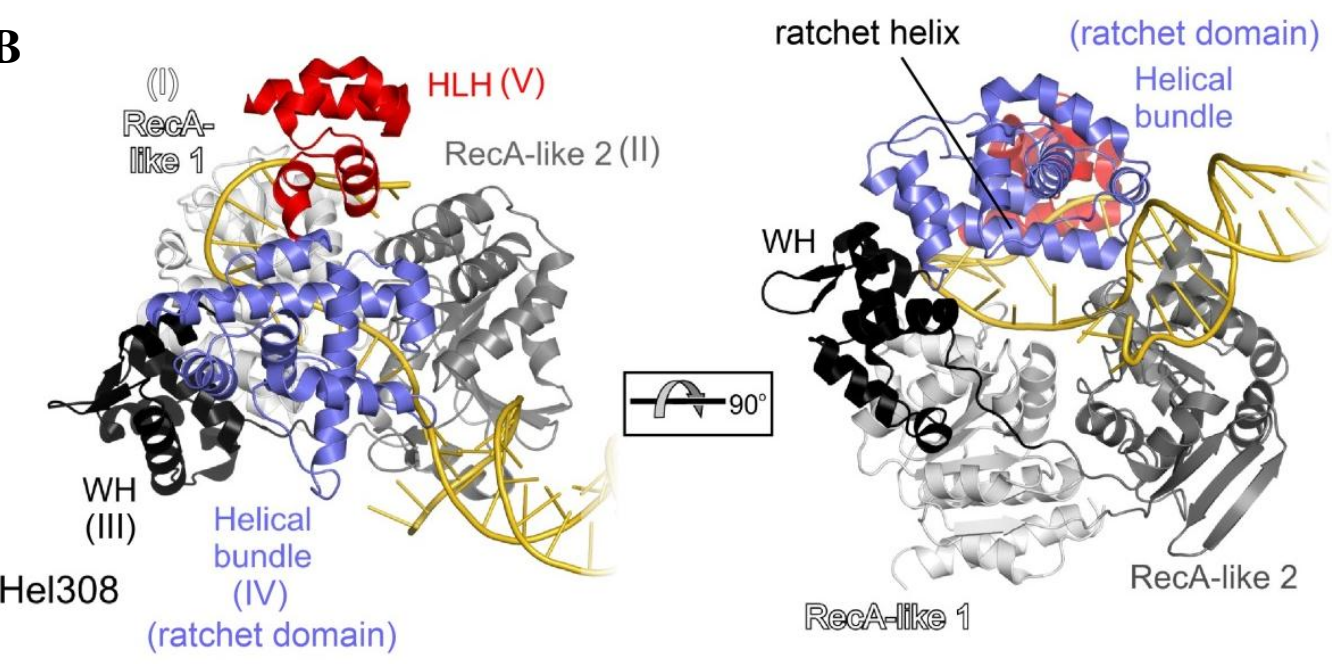

RReA-Allke 1

C

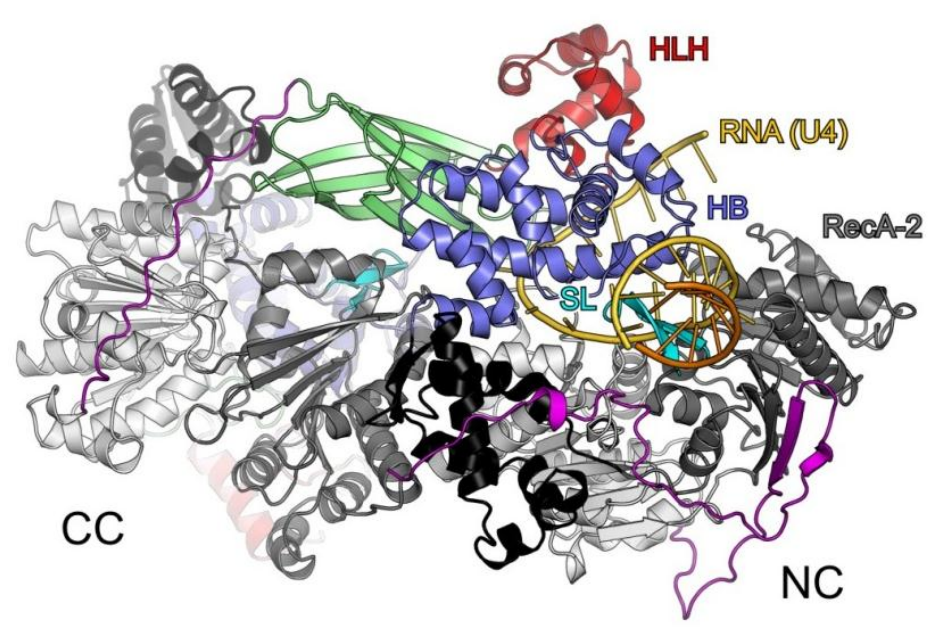

Figure 3.1 Similarity of domain organization between Brr2 and Hel308.

(A) Schematic representation of the domain organization in Hel308 and Brr2. RecA-like domains, light and dark gray; WH domain, black; helical bundle domain (ratchet), blue; HLH domain, red. Ribbon plots of the Hel308 DNA helicase in complex with DNA (B) (Buttner et al., 2007) (PDB ID 2P6R), and the Brr2 helicase cassettes with a modeled RNA (Santos et al., 2012). DNA or RNA, gold; Brr2 N-terminal extension and intercassette linker, magenta. 
respect, I show that while Brr2 efficiently bound and unwound the wildtype yeast U4/U6 (pre-bound to Snu13 to stabilize the U4 5'-stem loop), it did not bind the blunt end U4/U6 variant lacking the 5' and 3' single stranded overhangs (U4 $\left.{ }^{1-64} / \mathrm{U6}^{55-81}\right)$ (Mol. Cell, 2009, Figure S4 and Figure S7). Furthermore, the unwinding of this truncated U4/U6 was dramatically reduced, which arises from the reduced formation of functional Brr2-RNA complexes (Mol. Cell, 2009, Figures 4 and 7B).

\subsection{The helical bundle domain of the N-Sec63 unit of Brr2 may act as a ratchet by directly contacting RNA}

In Hel308, the analog of the helical bundle domain of Sec63 unit has been suggested to act as a ratchet. Notably, removal of this domain uncouples the ATP hydrolysis and helicase activity, and an equivalent of this domain is absent in many non-translocating helicases such as DEAD-box RNA helicases (Büttner et al., 2007; Sengoku et al., 2006). All these pieces of evidence suggest that this domain is required to maintain the processive translocation of Ski2-like helicases. A long central helix in the equivalent HB domain of Hel308 directly contacts the 3'-ssDNA, where a positively charged residue (Arg) and an aromatic residue (Trp) stack on the base moieties. Similar to the Hel308, the long scaffolding helix of the N-Sec63 HB domain runs along the presumed RNA-binding tunnel and aromatic (F1100) and positively charged side chains (R1107 and R1110) protrude from the underside of this helix and are predicted to intermittently contact the RNA during the cycle of ATP hydrolysis and translocation (Pena et al., 2009). In agreement with the importance of these residues, mutation of R1107 and R1110 resulted in a defect in the splicing of pre-U3 RNA and could completely abolish the RNA unwinding activity of Brr2, respectively (Mol. Cell, 2009, Figures 5B, 6D and 7D). Very recently, a number of mutations in human Brr2 were discovered to give rise to a severe type of autosomal dominant retinitis pigmentosa (RP33), a progressive retinal dystrophy. Interestingly, two of these mutations reside in the corresponding ratchet helix of human Brr2 (S1087L and R1090L), the yeast equivalents of which (N1104L and R1107L), impaired unwinding of U4/U6 within the tri-snRNPs (Liu et al., 2012; Benaglio et al., 2011; Li et al., 2010; Zhao et al., 2009). Furthermore, I observed that upon S1087L (RP33-linked) mutation in a human Brr2 variant encompassing the entire helicase region $\left(\mathrm{hBrr} 2^{\mathrm{HR}}\right.$ ), the helicase activity was dramatically reduced (PNAS, 2012, Figure S7) and both the RNA-stimulated 
ATP hydrolysis and the RNA binding to a 12 bp RNA duplex were significantly affected (by $\sim 2$-fold) compared to the wildtype.

All together, these findings indicate the crucial function of HB domain of the N-Sec63 unit in the unwinding mechanism of Brr2 through acting as a ratchet that couples conformational changes to nucleic acid translocation, in a manner similar to the case of Hel308.

\subsection{Brr2 consists of active N-terminal and non-active C-terminal helicase cassettes}

Previously, genetic analyses have shown that only the helicase activity of the N-terminal cassette is required for pre-mRNA splicing (Kim and Rossi, 1999). The C-terminal cassette bears non-canonical helicase motifs, which are thought to render it inactive (Zhang, et al., 2009; Pena et al., 2009), and is generally considered as a versatile platform mediating protein-protein interaction (van Nues and Beggs, 2001). Whether the C-terminal cassette also influences activities of the N-terminal cassette directly and if so how, was unknown. Recent X-ray crystal structure of a large fragment of human Brr2 encompassing both helicase regions, determined by K. Santos in the group of Markus C. Wahl, revealed direct interaction of both of the Hel308-like $\mathrm{N}$-terminal $\left(\mathrm{Brr} 2^{\mathrm{NC}}\right.$ ) and C-terminal (Brr2 ${ }^{\mathrm{CC}}$ ) helicase cassettes (PNAS, 2012). These extensive interactions are established primarily through the IG domain of the N-terminal cassette, which is fitted squarely between the WH domain and the RecA2 domain of the C-terminal cassette. Additional contacts ensue between the RecA2 domain of the C-terminal cassette and the RecA1 and the WH domains of the N-terminal cassette. However, the crystallized fragment lacked the Brr2's Nterminal tail (ca. 400 amino acids) that may mediate additional contacts with the helicase region. Consistently with previous in vivo experiments, I showed that $\mathrm{hBrr} 2^{\mathrm{NC}}$ is the catalytic helicase cassette of Brr2, while the $\mathrm{hBrr}^{\mathrm{CC}}$ was inactive in both ATPase and U4/U6 unwinding activities (PNAS, 2012, Figure 2B, 2C). The RecA2 domain of processive helicases contain a hairpin loop that is ideally positioned to plow through the nucleic acid duplex upon forward movement and thus acts as a strand separation device. Mutation of the separator loop can abolish the helicase activity in other helicases (Lam et al., 2003). Significantly, removal of the separator loop of $\mathrm{Brr} 2^{\mathrm{NC}}$ rendered it unable to support cellular growth (Mol. Cell, 2009, Figure 6A). The lethal phenotype confirms the 
crucial function of this element in Brr2-mediated unwinding of U4/U6. Furthermore, in line with the conclusion that the C-terminal cassette of Brr2 is not directly involved in melting the dssRNA substrate, I show that truncation of the $\beta$-hairpin loop of the $\mathrm{Brr} 2^{\mathrm{CC}}$ had no effect on either Brr2 enzymatic activity or its RNA binding (PNAS, 2012, Figure 2A and Figure 4). This could also indicate that the RNA does not enter the second helicase cassette of Brr2 and should take another path (see below).

\subsection{The C-terminal pseudohelicase domain of Brr2 acts as an intramolecular cofactor}

Interestingly, the isolated $\mathrm{Brr} 2^{\mathrm{NC}}$, compared with the $\mathrm{Brr} 2$ variant containing both helicase domains, exhibited an approximately 2-fold decrease in RNA-stimulated ATPase activity and a dramatic reduction of helicase activity both towards its complex U4/U6 snRNA substrate and a short linear RNA duplex (PNAS, 2012, Figure 2B, 2C). Given that there is an extensive interface between the $\mathrm{N}$ - and $\mathrm{C}$-terminal cassettes, these results suggest that the C-terminal cassette is an intramolecular cofactor of the N-terminal helicase. The importance of this interaction surface for the communication of cassettes was further elucidated by mutational analysis of the interacting residues. As I showed here, the majority of single alanine substitutions located at the interface of the $\mathrm{N}$-terminal RecA1 or WH domains and the C-terminal RecA2 domain (R603A, R637A, K1544A, H1548A and T1578A) impaired the U4/U6 unwinding activity of Brr2. However, as revealed by the anisotropy experiments, the K1544A mutant could still bind RNA in a manner similar to the binding by the wildtype protein (PNAS, 2012, Figures 4E-H). Additionally, I examined the effects of alterations in the linker between the helicase cassettes. Indeed, mutations in the inter-cassette linker that contact the N-terminal IG (ILP1290-2AAA) or C-terminal RecA-1 domain (LPV1307-9AAA) and also a reciprocal contact from the N-terminal IG domain to the linker (R1195A) caused significant defects in the helicase activity of the Nterminal cassette. Significantly, mutation of a triple proline motif in the centre of the linker (PPP1296-8AAA) with no direct contacts to Brr2 helicase regions reduced ATPase activities but strongly up-regulated helicase activity (PNAS, 2012, Figures 4E-G). These results suggest that the linker can transmit conformational changes to the N-terminal HLH and HB domains via the intervening IG domain. 
Despite lacking the ability to hydrolyze ATP, the Brr2 ${ }^{\mathrm{CC}}$ could stably bind ATP-Mg ${ }^{2+}$ after soaking the crystals in this solution (Santos et al., 2012). Strikingly, mutation of residues in the ATP binding pocket that could interfere with the accommodation of ATP (G1355Q/K1356E) showed that ATP clamping by the Brr2 ${ }^{\mathrm{CC}}$ could have consequences on the overall enzymatic activity of Brr2 (PNAS, 2012, Figure 4). Thus, our data show for the first time that the $\mathrm{C}$-terminal cassette can regulate the $\mathrm{N}$-terminal helicase cassette form a distance and play a direct role in spliceosomal RNP remodeling events without contributing RNA helicase activity itself. Given that a number of proteins required for different steps of splicing interact with the C-terminal cassette (van Nues and Beggs, 2001), it is imaginable that these additional interactions may control the functionality of Brr2, as a permanent resident of the spliceosome, enabling it to perform its function reliably during the steps of activation and disassembly of the spliceosome.

\subsection{Implications for the path of RNA through Brr2}

As in Hel308 and the SF2 RNA helicase Mtr4, Brr2 is expected to thread one RNA strand through the central tunnel of the N-terminal cassette during duplex unwinding, while the separator loop is inserted into the RNA duplex region. The single stranded RNA should then contact the conserved RNA binding motifs of the RecA1 and RecA2 domains as well as the underside of the scaffolding ratchet helix of the HB domain (PNAS, 2012, Figures S5 and S6). Involvement of these motifs in RNA binding is supported by the yeast brr2-1 allele, which gives rise to a protein bearing an E610G exchange that impedes U4/U6 disnRNA unwinding (Raghunathan and Guthrie, 1998) and fails to release the excised intron and dissociate snRNAs during spliceosome disassembly (Small et al., 2006). The equivalent E591 of hBrr2 lies at the center of the helicase motif Ic and is exposed on the inner surface of the RNA-binding tunnel across the ratchet helix.

However, upon emergence from the N-terminal tunnel, the ssRNA may either exit via a positively charged surface on the N-terminal HLH domain in Hel308-like fashion or continue towards the $\mathrm{C}$-terminal cassette. Mutation of positively charged surface residues of the HLH domain (R1133E/K1134E) led to enhanced ATPase activity while the U4/U6 unwinding activity and binding to a model RNA duplex was reduced dramatically (PNAS, 2012, Figure 4). Similarly, in Hel308, a conserved triplet of arginines on the surface of its HLH domain has been proposed to engage ssDNA for coupling to productive ATP 
hydrolysis (Woodman et al., 2007). It is likely that the contacts of the HLH domain on the remote 3'-tail of the RNA strand is a key step in initiating the loading of Brr2 onto U4/U6 and transducing this to efficient ATP hydrolysis.

\subsection{Mechanism of RNP remodeling by Brr2 during spliceosome activation}

Previous studies have documented the 3' to 5' translocation of Hel308, Mer3 and Mtr4 on DNA or RNA strands; all members of the Ski2-like helicase subfamily (Bernstein et al., 2008; Guy and Bolt, 2005; Nakagawa and Kolodner, 2002). Consequently, the homology of Brr2 to these helicases suggests that Brr2 also acts by translocating in the 3 ' to 5 ' direction on its nucleic acid substrates. A 3' to 5' polarity would be well suited to initiate dissociation of the U4/U6 complex during spliceosome activation, since both U4 and U6 snRNAs exhibit single-stranded 3'-overhangs that may serve as entry points for Brr2. I showed that Brr2 binds to U4/U6 with high affinity $\left(\mathrm{K}_{\mathrm{d}} \sim 30 \mathrm{nM}\right)$ and that it exhibits higher specificity for unwinding of this complex three-way junction RNA structure than of a linear RNA duplex (18 bp) with a 3'-overhang. Furthermore, I demonstrated by constructing various mutants of U4/U6 snRNA that Brr2 is loaded onto the single-stranded central domain of U4 preceding the U4/U6 stem I and thus translocates in 3' to 5' direction to unwind stem I before stem II is unwound (Genes Dev., 2012, Figure 5). Notably, the presence of the 3'-overhang of U6 adjacent to U4/U6 stem II was not sufficient to allow loading and unwinding (Genes Dev., 2012). This model of U4 release may allow U6 to form U2/U6 helix Ia even before the stem II is disrupted. Indeed, these results are nicely consistent with previous report on the minor spliceosome that shares a homologous snRNA interaction network, demonstrating that during the activation step of minor spliceosomes, the stem I of U4atac/U6atac is also unwound prior to stem II and an alternative U12/U6atac helix Ia is formed (Frilander and Steitz, 2001). In parallel to our findings, recent in vivo crosslinking and cDNA sequencing (CRAC) by Hahn et al., (2012) revealed that the N-terminal cassette of yeast Brr2, and not the C-terminal cassette, is largely crosslinked to the U4 snRNA at U4/U6 stem I and sequences immediately 3' to this region. Remarkably, this CRAC analysis did not detect any RNA crosslink to the C-terminal helicase cassette of Brr2 which supports our model for the path of the central domain of U4 snRNA through the HLH domain of the N-terminal cassette. 
A number of RNA helicases also act as RNPases in vitro; i.e. they are capable of detaching bound proteins from nucleic acid substrates. Dissociation of proteins that recognize double-stranded regions could be a consequence of the helicase disrupting the duplex binding platform of the protein. It has been evidenced that Hel308 is capable of displacing streptavidin bound to biotinylated oligonucleotides in vitro (Richards et al., 2008). The separator loop employed by Hel308 to dissociate the substrate duplex may similarly allow to 'shave' proteins off single-stranded RNA strands (Buttner et al., 2007).

The U4/U6 interaction region in the pre-catalytic spliceosome binds several proteins. Protein 15.5K (Snu13) initiates protein assembly at a neighboring K-turn (Nottrott et al., 1999; Vidovic et al., 2000) and leads to the subsequent recruitment of proteins Prp31 and the ternary Prp3-Prp4-CypH complex to the 5'-stem loop of U4 and U4/U6 stem II (Nottrott et al., 2002). In addition, the 3'- region of U6 is bound to the LSm heptameric complex (LSm 2-LSm8) that can prevent Brr2 interaction with this region (Achsel et al., 1999). In our scenario of Brr2 action by walking on U4, after opening the stem I Brr2 may continue its translocation on the 5'-stem loop to destabilize proteins that are in contact with the three-way junction of U4/U6 or it may rapidly load onto the stem II, leaving the 5'stem loop intact. Additionally, internal base pairing of the U6 ISL and formation of U2/U6 helix Ia may also cooperate, leading to the fast melting of the U4/U6 stem I and stem II.

\subsection{The Prp8 RNase H-like domain interacts specifically with U4/U6 SnRNA}

Earlier two-hybrid data indicated that the largest spliceosomal protein Prp8 interacts with Brr2 through its C-terminal region (Liu et al., 2006). Furthermore, it shown was very recently that a C-terminal fragment of Prp8 could bind and modulate Brr2 activity (Maeder et al., 2009, Mol. Cell, 2009). However, the mechanism whereby it regulates Brr2 activity is unclear. The Prp8 C-terminal region contains a domain with a three-dimensional fold resembling RNase $\mathrm{H}$, flanked on one side by a $\beta$-hairpin loop and on the other by an $\alpha$ helical domain (Pena et al. 2008; Ritchie et al. 2008; Yang et al. 2008). It also contains a Jab1/MPN-like domain that has lost its deubiquitination activity, but retained its ability to bind ubiquitin (Bellare et al. 2006). 
Here, I have provided evidence that within the C-terminal portion of Prp8, the RNase $\mathrm{H}$ domain and not the Jab1/MPN domain function as an RNA binding unit of Prp8 and that it specifically interacts with the yeast U4/U6 snRNAs in vitro, with a $\mathrm{K}_{\mathrm{d}}$ value of $\sim 1.5 \mu \mathrm{M}$ (Genes Dev., 2012, Figures 1-2 and Figure S1). Earlier studies led to reports of a weak affinity of the isolated RNase $\mathrm{H}$ domain $\left(\mathrm{K}_{\mathrm{d}}\right.$ of $\left.\sim 20 \mu \mathrm{M}\right)$ for a four-helix junction RNA construct mimicking the U2/U6-5'splice site (Ritchie et al., 2008). Binding studies using various deletion mutants, combined with the results from UV crosslinking and from RNase protection assays demonstrate that the RNase $\mathrm{H}$ domain requires single-stranded regions of the U4 and U6 snRNAs preceding U4/U6 stem I, with the single-strand region of U4 contributing decisively to RNA-protein complex formation. Interestingly, this interaction was not dependent on the sequence of the U4 central domain, as it could be inverted without hindering complex formation (Genes Dev., 2012, Figures 1-3 and Figure S2). Therefore, the particular three-way junction structure of U4/U6 appear to be important for the affinity of the Prp8 RNase H domain for binding, as modifying the 5'-stem loop of U4 could also affect complex formation (Genes Dev., 2012, Figure 2).

Notably, on the basis of the structural probing data with purified human and yeast trisnRNPs, the central domain of U4 is either inaccessible (in case of humans) or somewhat less accessible (in the case of yeast) for chemical modification, indicating that within the U4/U6.U5 tri-snRNP, this region of the U4 snRNA can potentially be protected by proteins (Mougin et al., 2002).

\subsection{Mapping of the U4/U6 interaction site on the Prp8 RNase H domain}

Previously, crosslinking studies with the human B-complex revealed a crosslink between the 5'-splice site of pre-mRNA and a $33_{10}$-helix within the Prp8 RNase $\mathrm{H}$ central channel (Reyes et al., 1996 and 1999; see also Genes Dev., 2012, Figure S1,). This result could be reproduced with the isolated RNase $\mathrm{H}$ domain and the U2/U6-5'splice site four-helixjunction RNA oligo (Ritchie et al., 2008). Our analysis of the in vitro reconstituted complex of the RNase $\mathrm{H}$ and a U4/U6 mimicking oligo by mass spectroscopy could map the binding site to a region at the base of the $\beta$-hairpin loop of the Prp8 RNase $\mathrm{H}$ domain (Genes Dev., 2012, Table 1, Figure S3 and Figure 4). The importance of this region was further supported by a splicing defect observed upon mutating the crosslinked tyrosine of Prp8 to alanine (Prp8 ${ }^{\mathrm{Y} 1858 \mathrm{~A}}$; Figure S4 in Genes Dev., 2012). Strikingly, mutations in a 
similar region of Prp8 have been indicated to suppress a U4 cold-sensitive mutation (U4cs1) which hyperstabilizes the U4/U6 interaction and thus interferes with the U4/U6 unwinding process during spliceosome activation. Indeed, one of these suppressor mutations (RNase $\mathrm{H}^{\mathrm{V} 1860 \mathrm{D}}$ ) exhibited a lower affinity for binding to U4/U6 snRNA (Genes Dev., 2012, Figure S5). Thus, the physical interactions identified in this work are in agreement with the previous genetic interactions of Prp8 and U4 snRNA. As doublestranded nucleic acid is a common substrate of RNase $\mathrm{H}$ enzymes, it is possible to propose that the Prp8 RNase H domain accommodates the U4/U6 stem I within its central channel (Nielsen and Staley, 2012).

\subsection{A potential mechanism of Brr2 regulation by the Prp8 RNase $H$ domain}

Within the C-terminal portion of Prp8, the RNase H domain is followed by a Jab1/MPNlike domain. Indeed, I have defined the Jab1/MPN domain as a direct binding region of Prp8 to Brr2 and showed that the RNase $\mathrm{H}$ domain does not interact with Brr2 in vitro (Genes Dev., 2012, Figure 7B). Furthermore, I demonstrate that the RNase H domain interaction with the three-way junction structure of the U4/U6 snRNA hinders the Brr2mediated unwinding of U4/U6 in vitro (Genes Dev., 2012, Figure 7A). Since the RNase H domain has no direct affinity for Brr2, the inhibition of Brr2 activity may take place indirectly through sequestering the central domain of U4/U6, which is required as a loading site for Brr2 to initiate unwinding. This idea was corroborated by the results of the in vitro binding competition experiment, which showed that the binding of RNase $\mathrm{H}$ prevents Brr2 loading onto U4/U6, as no ternary complex of Brr2-U4/U6-RNase H was detected (Genes Dev., 2012, Figure 7B). These in vitro results are consistent with previous in vivo studies suggesting that Prp8 negatively regulates Brr2-mediated activation of the spliceosome (Kuhn et al., 2002; Kuhn and Brow, 2000; Kuhn and Brow, 1999).

On the basis of these findings, I propose that prior to the spliceosome activation, the interaction of the Prp8 RNase $\mathrm{H}$ domain with the U4/U6 snRNA is disrupted and Brr2 can react with its loading strand, the central domain of $U 4$, to initiate translocation and remodeling of the U4/U6 snRNPs. Furthermore, our results support the previous models suggesting that the RNase $\mathrm{H}$ domain of Prp8 provides an RNA binding platform that is 
involved in the handover of the 5'ss from U1 snRNA to U6 snRNA (Pena et al. 2008; Ritchie et al. 2008; Yang et al. 2008) (Genes Dev., 2012, Figure 4B).

\subsection{The Prp8 Jab1/MPN-like domain induces a locked conformation of Brr2}

The helicases Prp8 and Brr2 are stable components of the U5 snRNP, and upon assembly with the U4/U6 snRNPs to form the U4/U6.U5 tri-snRNPs, Brr2 helicase activity must be tightly controlled to prevent premature dissociation of U4/U6 particles. To date, a small number of mechanisms of regulation of RNA helicases by cofactor proteins, acting in a cis or trans manner, have been discovered within various helicase families (for examples, refer to the introduction). However, possible molecular mechanisms of regulation of members of the Ski2-like helicase family had remained to be characterized.

In the work for this thesis I aimed to unravel the molecular details of the process whereby a deubiquitinase-like domain, the Prp8 Jab1-MPN, regulates the Ski2-like helicase Brr2. Our biochemical studies on the Brr2-Prp8 Jab1/MPN complex combined with the crystal structure of the hBrr2 ${ }^{\mathrm{HR}}$-hPrp8 Jab1/MPN complex obtained in Markus Wahl's laboratory, revealed an inhibitory mechanism of Prp8 on Brr2 through intermittent occlusion of the RNA binding tunnel of Brr2 by the C-terminal acidic tail of the Prp8 Jab1/MPN domain (Submitted manuscript, Figures 1-2). This is achieved through extensive interaction of the Prp8 C-terminal tail with the conserved RNA binding motifs at the interior of the Nterminal helicase cassette of Brr2. In this way, Brr2's catalytic core is blocked from gaining access to the U4 central domain, an event which seems to be essential for initiating the process of spliceosome activation (Nielsen and Staley, 2012; Mozaffari-Jovin et al., 2012; Hahn et al., 2012). Since Brr2 has been implicated in functioning twice during the splicing cycle (Small et al., 2006), i.e. during the spliceosome's activation step and its disassembly, this inhibitory mechanism can provide the possibility of keeping Brr2 switched off until the stage which requires its activity. Moreover, as the Prp8 RNase H domain could also sequester Brr2's targeting site on U4/U6, it is conceivable that both neighboring Prp8 RNase H and Jab1/MPN domains act in a coordinated manner to prevent premature activation of Brr2 within the pre-catalytic spliceosome (B complex). In this scenario, accommodation of the 5'-splice site-U6 RNA duplex within the Prp8 RNase H channel may make the U4 central domain free for Brr2 loading. Subsequently, upon the 
clearance of the Prp8 C-terminal tail from Brr2's RNA binding channel, Brr2 can be introduced to its targeting site on the U4 snRNA (Figure 3.2).

\subsection{Molecular mechanism of Brr2 activation by the Prp8 Jab1/MPN domain}

The Prp8 Jab1/MPN domain is a derivative of the $\mathrm{Zn}^{2+}$-dependent isopeptidases that has lost its deubiquitinase activity, while retaining the ability to bind ubiquitin (Bellare et al., 2006). The C-terminus of the Prp8 Jab1 domain constitutes a tail which is unstructured and contains a large number of charged residues that are involved in the interaction of the tail with the RNA binding motifs of Brr2. Indeed, lack of a rigid structure may facilitate displacement of the Prp8 tail from the Brr2's RNA channel at the expense of subtle changes in the binding thermodynamics. Previously, disruption of the interaction of a Prp8conjugated ubiquitin with the Jab1/MPN domain has been suggested to trigger activation of the spliceosome (Brow, 2009; Bellare et al., 2008). Additionally, there is strong evidence that the GTPase, Snu114, which is a stable binding partner of Prp8, is involved in activation process of Brr2 (Small et al., 2008). Indeed, within the complex environment of the spliceosome, post-translational modifications or additional binding partners could potentially induce a signal for the release of the Prp8 C-terminal tail from Brr2's RNA pocket and trigger its activation.

I provide further evidence that subtle changes in the interaction of the most $\mathrm{C}$-terminal tail of Jab1 with Brr2's RNA binding channel not only leads to the release of the locked conformation of Brr2, but also stimulates the helicase activity of Brr2 (Submitted manuscript, Figures 3 and S3). Indeed, after loading of the U4 central domain into the catalytic core of Brr2, binding of the Jab1 domain is required that could configure Brr2 to efficiently remodel the U4/U6 snRNPs so that Jab1 acts as Brr2's coactivator protein (Figure 3.2). I demonstrate that the observed stimulation of Brr2-catalyzed unwinding of U4/U6 by the Prp8 Jab1 domain is due to the more efficient coupling between the Brr2's ATP hydrolysis and productive RNA strand separation when it is in complex with the Jab1 domain (Submitted manuscript, Figure 3). The crystal structure of the $\mathrm{hBrr} 2^{\mathrm{HR}}-\mathrm{hPrp} 8$ Jab1/MPN could have implications for the mechanism of this stimulatory effect. In this complex, the proximal tail of the Prp8 Jab1 domain is placed along a cleft between the HB and the HLH domains. The HB domain is thought to act as a helicase ratchet during 
helicase translocation on the newly unwound ssRNA, while the HLH domain is involved in coupling nucleic acid binding to productive ATP hydrolysis by positioning the unwound ssRNA relative to the HB domain (Figure 3.1B). Interactions between these two domains are critical for the helicase activity in Hel308 (Woodman et al., 2007). Since Brr2 lacks direct contacts between the HB and the HLH domains (PNAS, 2012), the Jab1 domain could help positioning these domains relative to each other.

In contrast to most of the short RNA duplexes formed within the spliceosome, the U4/U6 di-snRNAs is extensively base-paired and is highly stable. Therefore, Brr2 is expected to exert an appreciable degree of processivity in vivo, to be able to fully unwind the relatively long U4/U6 stem II (Maeder et al., 2009). Here, I demonstrate that Brr2 requires the globular domain of the Prp8 Jab1 to processively unwind RNA duplexes in vitro (Submitted manuscript, Figure 4). In line with the gain of processivity, interaction of the Jab1 globular domain increased the affinity of Brr2 for binding to the ssRNA (Submitted manuscript, Figure 2B). Thus, subsequent to loading of the RNA substrate by Brr2, during the spliceosome activation, the Prp8 interaction is still essential for Brr2 to efficiently remodel the U4/U6 snRNPs without repeated dissociation from its substrate.

Strikingly, I find that the characterized cooperation between the Brr2's helicase cassettes (PNAS, 2012), which is required for the helicase activity, is also essential to confer this helicase the efficient capacity of regulation by the Prp8 Jab1 domain. An explanation for this behavior could be provided by the repositioning of the $\mathrm{N}$-terminal helicase cassette relative to the C-terminal cassette upon Jab1 binding, observed in the hBrr $2^{\mathrm{HR}}$-hPrp8 Jab1 structure (Submitted manuscript, Figures S2 and S4). Indeed, disruption of the intercassette interactions could be an additional mechanism to efficiently inhibit the Brr2 helicase activity. Furthermore, this indicates that the N-terminal helicase cassette is dependent on the C-terminal cassette for efficient translocation on an RNA strand. 


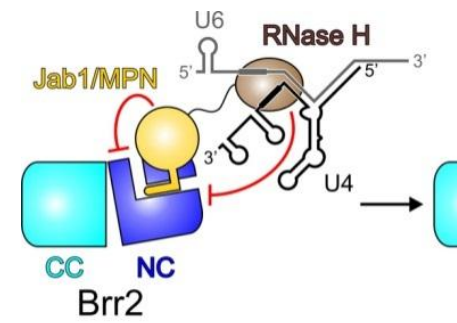

I.

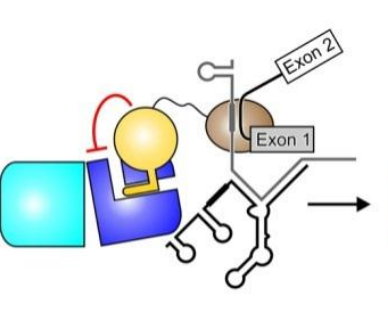

II.

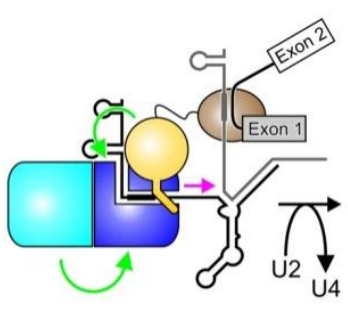

III.

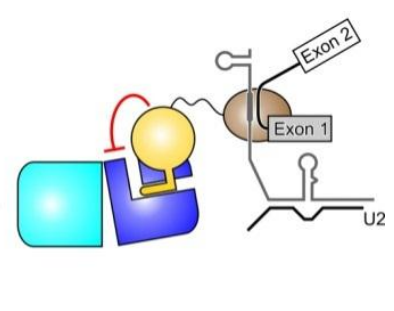

IV.

Figure 3.2 Molecular mechanism of the regulation of Brr2 helicase by Prp8 during the spliceosome activation.

Model of the regulation of Brr2 by the Prp8 RNase H and Jab1/MPN domains. Red lines, inhibitory effects; green arrows, stimulatory effects; magenta arrow, Brr2 translocation direction. (I) In the Bcomplex, Brr2 is blocked by the Prp8 Jab1/MPN domain through occlusion of Brr2's RNA pocket and disrupting Brr2 N-terminal cassette (NC) - C-terminal cassette (CC) interaction. Additionally, the Prp8 RNase H domain interacts with the Brr2 loading site, the U4 central domain (thick black line), and prevents Brr2 loading on its RNA substrate and initiation of U4/U6 unwinding. (II) After introducing the 5'ss/U6 ACAGAG-box (thick gray line) to the RNase H, the U4 snRNA is released. (III) Brr2 activation upon removal of the Prp8 C-terminal tail from Brr2's RNA pocket and initiation of the U4/U6 unwinding process with the stimulatory function of the Jab1 domain and the C-terminal cassette. (IV) After the spliceosome catalytic activation, the Prp8 Jab1 domain may again switch Brr2 off until the disassembly step.

\subsection{Molecular basis of the defects caused by the retinitis pigmentosa linked mutations in Prp8}

The pathogenesis of the splicing-related retinitis pigmentosa (RP) has been suggested to arise from the reduced amounts of the spliceosomal components such as the tri-snRNPs levels, and thus reduced rate of splicing in the retinal cells (Cao et al., 2011; Linder et al.,2011).

On the basis of our data, RP-linked mutations in Prp8 can be divided into three groups (Submitted manuscript, Figure 5A). The first group includes mutations in the globular portion of the Jab1/MPN domain that can affect the structural folding/stability of the Jab1 domain and thus, impairs the binding and the stimulatory mechanism of Brr2 (Maeder et 
41 Discussion

al., 2009; Brow, 2009). These mutations caused strong defects in splicing and yeast growth phenotype (Submitted manuscript, Figures 5 and S5). Therefore, decreased level of trisnRNPs formation and a defect in Brr2 activation could be the major consequences of these mutations. The second group of RP mutations reside in the proximal tail of the Jab1 domain that establish important interactions with both the HB and HLH domains of Brr2. As revealed by our results, similarly to the previous group, mutation of these residues (human: R2310 and F2314; yeast: R2388 and F2392) significantly impairs binding of the Jab1 domain to Brr2 and also reduces the level of functional tri-snRNPs (Boon et al., 2007) and leads to deleterious effects on splicing and cell viability (Submitted manuscript, Figure S5). The third class of mutations (for example in human: Q2321stop and Y2334; and in Yeast: A2399stop and F2412N) is located in the distal region of the Jab1 tail and showed no obvious effects in binding of the Jab1 domain to Brr2 (Submitted manuscript, Figures 5B and S6). These RP mutations, in vitro, abrogate the inhibitory mechanism of the Prp8 Jab1 domain on Brr2 (Submitted manuscript, Figure 5C-E). Importantly, as the amounts of tri-snRNPs did not alter in this set of mutations; we expect that a similar in vivo dysfunction in the inhibitory mechanism of Prp8 Jab1 domain on Brr2 could be the disease principle for these RP mutations (Submitted manuscript, Figures S5 and S6). Conceivably, loss of an inhibitory checkpoint may lead to premature activation of the spliceosome.

I conclude that RP mutations in both Prp8 and the spliceosomal helicase Brr2 have a large impact on the activation process of the spliceosome, and that this - together with the assembly defect of the spliceosomal subunits - makes up the basis for the molecular pathology of the retinal disease. 


\section{Perspectives}

The work described above not only deepened our understanding of the structural and functional mechanism of Brr2 and its regulation by the Prp8 C-terminal domains; it also provided novel insights into the cascade of spliceosome activation. Moreover, it provided a structure- and mechanism-based understanding of how mutations in the Jab1 domain of Prp8 may give rise to retinitis pigmentosa. Nevertheless, several interesting questions concerning the action and regulation of Brr2 in spliceosome activation remain poorly understood.

A remarkable functional aspect of some RNA helicases is their ability to displace RNAprotein complexes. In this respect it will be interesting to investigate in the future whether the Brr2-Prp $8^{\mathrm{Jab} 1 / \mathrm{MPN}}$ complex can displace the various proteins which are associated with U4/U6 RNAs within the purified U4/U6 snRNPs, and in which manner their release takes place. Of great importance will be the investigation of the various modes of regulation of Brr2 by Prp8 in the context of the entire spliceosome. Ideally this should be done with a purified splicing system which allows one to reconstitute the transformation of a $\mathrm{B}$ complex to the activated spliceosome with purified components, along the lines described for the catalytic phase of the spliceosome (Warcocki et al., 2009). This would allow delineation of the sequence of events and/or identification of the factors which alleviate the inhibition of Brr2 loading onto U4 RNA and activation of its helicase action, and would allow the possible role of ubiquitination of Prp8 and of the GTPase Snu114 in the regulation of Brr2 helicase to be addressed. Finally, once stem cells from retinitis pigmentosa patients harboring mutations in the Jab1 domain of Prp8 are available, it will be very interesting to analyze possible defects of pre-mRNA splicing on a global scale and to correlate the splicing defects with the misregulation of Brr2 described in this work. 


\section{References}

Achsel T, Brahms H, Kastner B, Bachi A, Wilm M, Lührmann R. (1999) A doughnutshaped heteromer of human Sm-like proteins binds to the 3'-end of U6 snRNA, thereby facilitating U4/U6 duplex formation in vitro. EMBO J. 18:5789-802.

Achsel T, Ahrens K, Brahms H, Teigelkamp S, Lührmann R. (1998) The human U5$220 \mathrm{kD}$ protein (hPrp8) forms a stable RNA-free complex with several U5-specific proteins, including an RNA unwindase, a homologue of ribosomal elongation factor EF-2, and a novel WD-40 protein. Mol Cell Biol. 18:6756-66.

Ajuh P, Kuster B, Panov K, Zomerdijk JC, Mann M, Lamond AI. (2000) Functional analysis of the human CDC5L complex and identification of its components by mass spectrometry. EMBO J. 19(23):6569-81.

Alcázar-Román AR, Tran EJ, Guo S, Wente SR. (2006) Inositol hexakisphosphate and Gle1 activate the DEAD-box protein Dbp5 for nuclear mRNA export. Nat Cell Biol. 8:711-6.

Andersen CB, Ballut L, Johansen JS, Chamieh H, Nielsen KH, Oliveira CL, Pedersen JS, Séraphin B, Le Hir H, Andersen GR. (2006) Structure of the exon junction core complex with a trapped DEAD-box ATPase bound to RNA. Science. 313:1968-72.

Bartels C, Klatt C, Lührmann R, Fabrizio P. (2002) The ribosomal translocase homologue Snu114p is involved in unwinding U4/U6 RNA during activation of the spliceosome. EMBO Rep. 3:875-80.

Bellare P, Small EC, Huang X, Wohlschlegel JA, Staley JP, Sontheimer EJ. (2008) A role for ubiquitin in the spliceosome assembly pathway. Nat Struct Mol Biol. 15:444-51.

Bellare P, Kutach AK, Rines AK, Guthrie C, Sontheimer EJ. (2006) Ubiquitin binding by a variant Jab1/MPN domain in the essential pre-mRNA splicing factor Prp8p. RNA. 12:292302.

Benaglio P, McGee TL, Capelli LP, Harper S, Berson EL, Rivolta C. (2011) Next generation sequencing of pooled samples reveals new SNRNP200 mutations associated with retinitis pigmentosa. Hum Mutat. 32:E2246-58.

Beran RK, Serebrov V, Pyle AM. (2007) The serine protease domain of hepatitis C viral NS3 activates RNA helicase activity by promoting the binding of RNA substrate. J Biol Chem. 282:34913-20. Erratum in: J Biol Chem. 2008 Feb 29;283(9):5971.

Bernstein J, Patterson DN, Wilson GM, Toth EA. (2008) Characterization of the essential activities of Saccharomyces cerevisiae Mtr4p, a 3'->5' helicase partner of the nuclear exosome. J Biol Chem. 283:4930-42. 
Berglund JA, Chua K, Abovich N, Reed R, Rosbash M. (1997) The splicing factor BBP interacts specifically with the pre-mRNA branchpoint sequence UACUAAC. Cell. 89:7817.

Bleichert F, Baserga SJ. (2007) The long unwinding road of RNA helicases. Mol Cell 27:339-352.

Boon KL, Grainger RJ, Ehsani P, Barrass JD, Auchynnikava T, Inglehearn CF, Beggs JD. (2007) prp8 mutations that cause human retinitis pigmentosa lead to a U5 snRNP maturation defect in yeast. Nat Struct Mol Biol. 14:1077-83.

Brow DA. (2009) Eye on RNA unwinding. Nat Struct Mol Biol. 16:7-8.

Brow DA. (2002) Allosteric cascade of spliceosome activation. Annu Rev Genet. 36:33360 .

Brow DA, Guthrie C. (1988) Spliceosomal RNA U6 is remarkably conserved from yeast to mammals. Nature. 334:213-8.

Burke JE, Sashital DG, Zuo X, Wang YX, Butcher SE. (2012) Structure of the yeast U2/U6 snRNA complex. RNA. 18:673-83.

Büttner K, Nehring S, Hopfner KP. (2007) Structural basis for DNA duplex separation by a superfamily-2 helicase. Nat Struct Mol Biol. 14:647-52.

Cao H, Wu J, Lam S, Duan R, Newnham C, Molday RS, Graziotto JJ, Pierce EA, Hu J. (2011) Temporal and tissue specific regulation of RP-associated splicing factor genes PRPF3, PRPF31 and PRPC8--implications in the pathogenesis of RP. PLoS One. 6:E15860.

Caruthers JM, McKay DB. (2002) Helicase structure and mechanism. Curr Opin Struct Biol. 12:123-33.

Chen HC, Cheng SC. (2012) Functional roles of protein splicing factors. Biosci Rep. $32: 345-59$.

Cordin O, Banroques J, Tanner NK, Linder P. (2006) The DEAD-box protein family of RNA helicases. Gene. 367:17-37.

Cordin O, Tanner NK, Doère M, Linder P, Banroques J. (2004) The newly discovered Q motif of DEAD-box RNA helicases regulates RNA-binding and helicase activity. EMBO J. 23:2478-87.

Danin-Kreiselman M, Lee CY, Chanfreau G. (2003) RNAse III-mediated degradation of unspliced pre-mRNAs and lariat introns. Mol Cell. 11:1279-89.

Delagoutte E, von Hippel PH. (2002) Helicase mechanisms and the coupling of helicases within macromolecular machines. Part I: Structures and properties of isolated helicases. Q Rev Biophys. 35:431-78. 
Fabrizio P, Laggerbauer B, Lauber J, Lane WS, Lührmann R. (1997) An evolutionarily conserved U5 snRNP-specific protein is a GTP-binding factor closely related to the ribosomal translocase EF-2. EMBO J. 16:4092-106.

Frick DN. (2007) The hepatitis C virus NS3 protein: a model RNA helicase and potential drug target. Curr Issues Mol Biol. 9:1-20.

Frilander MJ, Steitz JA. (2001) Dynamic exchanges of RNA interactions leading to catalytic core formation in the U12-dependent spliceosome. Mol Cell. 7:217-26.

Gorbalenya, A.E., and Koonin, E.V. (1993). Helicases: amino acid sequence comparisons and structure-function relationships. Curr. Opin. Struct. Biol. 3, 419-429.

Gottschalk A, Neubauer G, Banroques J, Mann M, Lührmann R, Fabrizio P. (1999) Identification by mass spectrometry and functional analysis of novel proteins of the yeast [U4/U6.U5] tri-snRNP. EMBO J. 18:4535-48.

Graveley BR. (2000) Sorting out the complexity of SR protein functions. RNA. 6:1197211.

Green MR. (1986) Pre-mRNA splicing. Annu Rev Genet. 20:671-708.

Grote M, Wolf E, Will CL, Lemm I, Agafonov DE, Schomburg A, Fischle W, Urlaub H, Lührmann R. (2010) Molecular architecture of the human Prp19/CDC5L complex. Mol Cell Biol. 30:2105-19.

Guthrie C, Patterson B. (1988) Spliceosomal snRNAs. Annu Rev Genet. 22:387-419.

Guy CP, Bolt EL. (2005) Archaeal Hel308 helicase targets replication forks in vivo and in vitro and unwinds lagging strands. Nucleic Acids Res. 33:3678-90.

Hahn D, Kudla G, Tollervey D, Beggs JD. (2012) Brr2p-mediated conformational rearrangements in the spliceosome during activation and substrate repositioning. Genes Dev. 26:2408-21.

Hastings ML, Krainer AR. (2001) Pre-mRNA splicing in the new millennium. Curr Opin Cell Biol. 13:302-9.

Henn A, Bradley MJ, De La Cruz EM. (2012) ATP utilization and RNA conformational rearrangement by DEAD-box proteins. Annu Rev Biophys. 41:247-67.

Ivings L, Towns KV, Matin MA, Taylor C, Ponchel F, Grainger RJ, Ramesar RS, Mackey DA, Inglehearn CF. (2008) Evaluation of splicing efficiency in lymphoblastoid cell lines from patients with splicing-factor retinitis pigmentosa. Mol Vis. 14:2357-66.

Jankowsky E. (2011) RNA helicases at work: binding and rearranging. Trends Biochem Sci. 36:19-29.

Jankowsky E, Fairman ME. (2007) RNA helicases--one fold for many functions. Curr Opin Struct Biol. 17:316-24. 
Kim DH, Rossi JJ. (1999) The first ATPase domain of the yeast 246-kDa protein is required for in vivo unwinding of the U4/U6 duplex. RNA. 5:959-71.

Kiss T. (2004) Biogenesis of small nuclear RNPs. J Cell Sci. 117:5949-51.

Kiss T. (2001) Small nucleolar RNA-guided post-transcriptional modification of cellular RNAs. EMBO J. 20:3617-22.

Konforti BB, Konarska MM. (1994) U4/U5/U6 snRNP recognizes the 5' splice site in the absence of U2 snRNP. Genes Dev. 8:1962-73.

Korneeva NL, First EA, Benoit CA, Rhoads RE. (2005) Interaction between the NH2terminal domain of eIF4A and the central domain of eIF4G modulates RNA-stimulated ATPase activity. J Biol Chem. 280:1872-81.

Krämer A. (1996) The structure and function of proteins involved in mammalian premRNA splicing. Annu Rev Biochem. 65:367-409.

Kuhn AN, Reichl EM, Brow DA. (2002) Distinct domains of splicing factor Prp8 mediate different aspects of spliceosome activation. Proc Natl Acad Sci U S A 99:9145-9149.

Kuhn AN, Brow DA. (2000) Suppressors of a cold-sensitive mutation in yeast U4 RNA define five domains in the splicing factor Prp8 that influence spliceosome activation. Genetics 155:1667-1682.

Kuhn AN, Li Z, Brow DA. (1999) Splicing factor Prp8 governs U4/U6 RNA unwinding during activation of the spliceosome. Mol. Cell 3:65-75.

Laggerbauer B, Achsel T, Lührmann R. (1998) The human U5-200kD DEXH-box protein unwinds U4/U6 RNA duplices in vitro. Proc Natl Acad Sci U S A. 95:4188-92.

Laggerbauer B, Lauber J, Lührmann R. (1996) Identification of an RNA-dependent ATPase activity in mammalian U5 snRNPs. Nucleic Acids Res. 24:868-75.

Lam AM, Keeney D, Frick DN. (2003) Two novel conserved motifs in the hepatitis C virus NS3 protein critical for helicase action. J Biol Chem. 278:44514-24.

Lauber J, Fabrizio P, Teigelkamp S, Lane WS, Hartmann E, Luhrmann R. (1996) The HeLa 200 kDa U5 snRNP-specific protein and its homologue in Saccharomyces cerevisiae are members of the DEXH-box protein family of putative RNA helicases. EMBO J. 15:4001-15.

Lemm I, Girard C, Kuhn AN, Watkins NJ, Schneider M, Bordonné R, Lührmann R. (2006) Ongoing U snRNP biogenesis is required for the integrity of Cajal bodies. Mol Biol Cell. 17:3221-31.

Li N, Mei H, MacDonald IM, Jiao X, Hejtmancik JF. (2010) Mutations in ASCC3L1 on 2 q11.2 are associated with autosomal dominant retinitis pigmentosa in a Chinese family. Invest Ophthalmol Vis Sci. 51:1036-43. 
Liao XC, Colot HV, Wang Y, Rosbash M. (1992) Requirements for U2 snRNP addition to yeast pre-mRNA. Nucleic Acids Res. 20:4237-45.

Linder B, Dill H, Hirmer A, Brocher J, Lee GP, Mathavan S, Bolz HJ, Winkler C, Laggerbauer B, Fischer U. (2011) Systemic splicing factor deficiency causes tissuespecific defects: a zebrafish model for retinitis pigmentosa. Hum Mol Genet. 20:368-77.

Linder P, Daugeron MC. (2000) Are DEAD-box proteins becoming respectable helicases? Nat Struct Biol. 7:97-9.

Liu S, Rauhut R, Vornlocher HP, Lührmann R. (2006) The network of protein-protein interactions within the human U4/U6.U5 tri-snRNP. RNA. 12:1418-30.

Lee GH, Wasser S, Lim SG. (2008) Hepatitis B pregenomic RNA splicing--the products, the regulatory mechanisms and its biological significance. Virus Res. 136:1-7.

Liu T, Jin X, Zhang X, Yuan H, Cheng J, Lee J, Zhang B, Zhang M, Wu J, Wang L, Tian G, Wang W. (2012) A novel missense SNRNP200 mutation associated with autosomal dominant retinitis pigmentosa in a Chinese family. PLoS One. 7:E45464.

Liu F, Putnam A, Jankowsky E. (2008) ATP hydrolysis is required for DEAD-box protein recycling but not for duplex unwinding. Proc Natl Acad Sci U S A. 105:20209-14.

Long JC, Caceres JF. (2009) The SR protein family of splicing factors: master regulators of gene expression. Biochem J. 417:15-27.

Mackintosh SG, Raney KD. (2006) DNA unwinding and protein displacement by superfamily 1 and superfamily 2 helicases. Nucleic Acids Res. 34:4154-9.

Madhani HD, Guthrie C. (1994) Dynamic RNA-RNA interactions in the spliceosome. Annu Rev Genet. 28:1-26.

Maeder C, Kutach AK, Guthrie C. (2009) ATP-dependent unwinding of U4/U6 snRNAs by the Brr2 helicase requires the $\mathrm{C}$ terminus of Prp8. Nat Struct Mol Biol. 16:42-8.

Makarova OV, Makarov EM, Urlaub H, Will CL, Gentzel M, Wilm M, Lührmann R. (2004) A subset of human 35S U5 proteins, including Prp19, function prior to catalytic step 1 of splicing. EMBO J. 23:2381-91.

Makarova OV, Makarov EM, Liu S, Vornlocher HP, Lührmann R. (2002) Protein 61K, encoded by a gene (PRPF31) linked to autosomal dominant retinitis pigmentosa, is required for U4/U6*U5 tri-snRNP formation and pre-mRNA splicing. EMBO J. 21:114857.

Mallam AL, Del Campo M, Gilman B, Sidote DJ, Lambowitz AM. (2012) Structural basis for RNA-duplex recognition and unwinding by the DEAD-box helicase Mss116p. Nature. 490:121-5.

Martínez-Gimeno M, Gamundi MJ, Hernan I, Maseras M, Millá E, Ayuso C, GarcíaSandoval B, Beneyto M, Vilela C, Baiget M, Antiñolo G, Carballo M. (2003) Mutations in 
the pre-mRNA splicing-factor genes PRPF3, PRPF8, and PRPF31 in Spanish families with autosomal dominant retinitis pigmentosa. Invest Ophthalmol Vis Sci. 44:2171-7.

Montpetit B, Thomsen ND, Helmke KJ, Seeliger MA, Berger JM, Weis K. (2011) A conserved mechanism of DEAD-box ATPase activation by nucleoporins and InsP6 in mRNA export. Nature. 472:238-42.

Mougin A, Gottschalk A, Fabrizio P, Lührmann R, Branlant C. (2002) Direct probing of RNA structure and RNA-protein interactions in purified HeLa cell's and yeast spliceosomal U4/U6.U5 tri-snRNP particles. J Mol Biol. 317:631-49.

Mozaffari-Jovin S, Santos KF, Hsiao HH, Will CL, Urlaub H, Wahl MC, Lührmann R. (2012) The Prp8 RNase H-like domain inhibits Brr2-mediated U4/U6 snRNA unwinding by blocking Brr2 loading onto the U4 snRNA. Genes Dev. 26:2422-34.

Nakagawa T, Kolodner RD. (2002) The MER3 DNA helicase catalyzes the unwinding of holliday junctions. J Biol Chem. 277:28019-24.

Nielsen KH, Staley JP. (2012) Spliceosome activation: U4 is the path, stem I is the goal, and Prp8 is the keeper. Let's cheer for the ATPase Brr2! Genes Dev. 26:2461-7.

Nielsen KH, Chamieh H, Andersen CB, Fredslund F, Hamborg K, Le Hir H, Andersen GR. (2009) Mechanism of ATP turnover inhibition in the EJC. RNA. 15:67-75.

Nottrott S, Urlaub H, Lührmann R. (2002) Hierarchical, clustered protein interactions with U4/U6 snRNA: a biochemical role for U4/U6 proteins. EMBO J. 21:5527-38.

Nottrott S, Hartmuth K, Fabrizio P, Urlaub H, Vidovic I, Ficner R, Lührmann R. (1999) Functional interaction of a novel 15.5kD [U4/U6.U5] tri-snRNP protein with the 5' stemloop of U4 snRNA. EMBO J. 18:6119-33.

Özeş AR, Feoktistova K, Avanzino BC, Fraser CS. (2011) Duplex unwinding and ATPase activities of the DEAD-box helicase eIF4A are coupled by eIF4G and eIF4B. J Mol Biol. 412:674-87.

Patel AA, Steitz JA. (2003) Splicing double: insights from the second spliceosome. Nat Rev Mol Cell Biol. 4:960-70.

Patel SS, Donmez I. (2006) Mechanisms of helicases. J Biol Chem. 281:18265-8.

Pena V, Jovin SM, Fabrizio P, Orlowski J, Bujnicki JM, Lührmann R, Wahl MC. (2009) Common design principles in the spliceosomal RNA helicase Brr2 and in the Hel308 DNA helicase. Mol Cell. 35:454-66. Erratum in: Mol Cell. 2011 Feb 4;41(3):366.

Pena V, Rozov A, Fabrizio P, Lührmann R, Wahl MC. (2008) Structure and function of an RNase H domain at the heart of the spliceosome. EMBO J. 27:2929-40.

Ponting CP. (2000) Proteins of the endoplasmic-reticulum-associated degradation pathway: domain detection and function prediction. Biochem J. 351:527-35. 
Query CC, Strobel SA, Sharp PA. (1996) Three recognition events at the branch-site adenine. EMBO J. 15:1392-402.

Query CC, Moore MJ, Sharp PA. (1994) Branch nucleophile selection in pre-mRNA splicing: evidence for the bulged duplex model. Genes Dev. 8:587-97.

Rad B, Kowalczykowski SC. (2012) Efficient coupling of ATP hydrolysis to translocation by RecQ helicase. Proc Natl Acad Sci U S A. 109:1443-8.

Raghunathan PL, Guthrie C. (1998) RNA unwinding in U4/U6 snRNPs requires ATP hydrolysis and the DEIH-box splicing factor Brr2. Curr Biol. 8:847-55.

Raker VA, Plessel G, Lührmann R. (1996) The snRNP core assembly pathway: identification of stable core protein heteromeric complexes and an snRNP subcore particle in vitro. EMBO J. 15:2256-69.

Reyes JL, Gustafson EH, Luo HR, Moore MJ, Konarska MM. (1999) The C-terminal region of hPrp8 interacts with the conserved GU dinucleotide at the 5' splice site. RNA. 5:167-179.

Reyes JL, Kois P, Konforti BB, Konarska MM. (1996) The canonical GU dinucleotide at the $5^{\prime}$ splice site is recognized by p220 of the U5 snRNP within the spliceosome. RNA. 2:213-225.

Richards JD, Johnson KA, Liu H, McRobbie AM, McMahon S, Oke M, Carter L, Naismith JH, White MF. (2008) Structure of the DNA repair helicase hel308 reveals DNA binding and autoinhibitory domains. J Biol Chem. 283:5118-26.

Grainger RJ, Beggs JD. Prp8 (2005) protein: at the heart of the spliceosome. RNA. 11:53357.

Ritchie DB, Schellenberg MJ, Gesner EM, Raithatha SA, Stuart DT, Macmillan AM. (2008) Structural elucidation of a PRP8 core domain from the heart of the spliceosome. Nat Struct Mol Biol. 15:1199-205.

Russell R, Jarmoskaite I, Lambowitz AM. (2012) Toward a molecular understanding of RNA remodeling by DEAD-box proteins. RNA Biol. 10(1).

Rutz B, Séraphin B. (1999) Transient interaction of BBP/ScSF1 and Mud2 with the splicing machinery affects the kinetics of spliceosome assembly. RNA. 5:819-31.

Ryan DE, Abelson J. (2002) The conserved central domain of yeast U6 snRNA: importance of U2-U6 helix Ia in spliceosome assembly. RNA. 8:997-1010.

Sanford JR, Ellis J, Cáceres JF. (2005) Multiple roles of arginine/serine-rich splicing factors in RNA processing. Biochem Soc Trans. 33:443-6. 
Sashital DG, Cornilescu G, McManus CJ, Brow DA, Butcher SE. (2004) U2-U6 RNA folding reveals a group II intron-like domain and a four-helix junction. Nat Struct Mol Biol. 11:1237-42. Erratum in: Nat Struct Mol Biol. 2005 Jan;12(1):99.

Santos KF, Jovin SM, Weber G, Pena V, Lührmann R, Wahl MC. (2012) Structural basis for functional cooperation between tandem helicase cassettes in Brr2-mediated remodeling of the spliceosome. Proc Natl Acad Sci U S A. 109:17418-23.

Schwer B. (2008) A conformational rearrangement in the spliceosome sets the stage for Prp22-dependent mRNA release. Mol Cell. 30:743-54.

Schwer B, Meszaros T. (2000) RNA helicase dynamics in pre-mRNA splicing. EMBO J. 19:6582-91.

Semlow DR, Staley JP. (2012) Staying on message: ensuring fidelity in pre-mRNA splicing. Trends Biochem Sci. 37:263-73.

Sengoku T, Nureki O, Nakamura A, Kobayashi S, Yokoyama S. (2006) Structural basis for RNA unwinding by the DEAD-box protein Drosophila Vasa. Cell. 125:287-300.

Shiratori A, Shibata T, Arisawa M, Hanaoka F, Murakami Y, Eki T. (1999) Systematic identification, classification, and characterization of the open reading frames which encode novel helicase-related proteins in Saccharomyces cerevisiae by gene disruption and Northern analysis. Yeast. 15:219-53.

Silverman E, Edwalds-Gilbert G, Lin RJ. (2003) DExD/H-box proteins and their partners: helping RNA helicases unwind. Gene. 312:1-16.

Small EC, Leggett SR, Winans AA, Staley JP. (2006) The EF-G-like GTPase Snu114p regulates spliceosome dynamics mediated by Brr2p, a DExD/H box ATPase. Mol Cell. 23:389-99.

Staley JP, Guthrie C. (1999) An RNA switch at the 5' splice site requires ATP and the DEAD box protein Prp28p. Mol Cell. 3:55-64.

Stevens SW, Abelson J. (1999) Purification of the yeast U4/U6.U5 small nuclear ribonucleoprotein particle and identification of its proteins. Proc Natl Acad Sci U S A. 96:7226-31.

Tanackovic G, Ransijn A, Thibault P, Abou Elela S, Klinck R, Berson EL, Chabot B, Rivolta C. (2011) PRPF mutations are associated with generalized defects in spliceosome formation and pre-mRNA splicing in patients with retinitis pigmentosa. Hum Mol Genet. 20:2116-30.

Tanner NK, Cordin O, Banroques J, Doère M, Linder P. (2003) The Q motif: a newly identified motif in DEAD box helicases may regulate ATP binding and hydrolysis. Mol Cell. 11:127-38. 
Tanner NK, Linder P. (2001) DExD/H box RNA helicases: from generic motors to specific dissociation functions. Mol Cell 8:251-62.

Tarn WY, Steitz JA. (1997) Pre-mRNA splicing: the discovery of a new spliceosome doubles the challenge. Trends Biochem Sci. 22:132-7.

Towns KV, Kipioti A, Long V, McKibbin M, Maubaret C, Vaclavik V, Ehsani P, Springell K, Kamal M, Ramesar RS, Mackey DA, Moore AT, Mukhopadhyay R, Webster AR, Black GC, O'Sullivan J, Bhattacharya SS, Pierce EA, Beggs JD, Inglehearn CF. (2010) Prognosis for splicing factor PRPF8 retinitis pigmentosa, novel mutations and correlation between human and yeast phenotypes. Hum Mutat. 31:E1361-76.

Tseng CK, Liu HL, Cheng SC. (2011) DEAH-box ATPase Prp16 has dual roles in remodeling of the spliceosome in catalytic steps. RNA. 17:145-54.

Tsai RT, Fu RH, Yeh FL, Tseng CK, Lin YC, Huang YH, Cheng SC. (2005) Spliceosome disassembly catalyzed by Prp43 and its associated components Ntr1 and Ntr2. Genes Dev. 19:2991-3003.

van Nues RW, Beggs JD. (2001) Functional contacts with a range of splicing proteins suggest a central role for Brr2p in the dynamic control of the order of events in spliceosomes of Saccharomyces cerevisiae. Genetics. 157:1451-67.

Velankar SS, Soultanas P, Dillingham MS, Subramanya HS, Wigley DB. (1999) Crystal structures of complexes of PcrA DNA helicase with a DNA substrate indicate an inchworm mechanism. Cell. 97:75-84.

Vidovic I, Nottrott S, Hartmuth K, Lührmann R, Ficner R. (2000) Crystal structure of the spliceosomal 15.5kD protein bound to a U4 snRNA fragment. Mol Cell. 6:1331-42.

Villa T, Pleiss JA, Guthrie C. (2002) Spliceosomal snRNAs: $\mathrm{Mg}(2+)$-dependent chemistry at the catalytic core? Cell. 109:149-52.

von Hippel PH, Delagoutte E. (2001) A general model for nucleic acid helicases and their "coupling" within macromolecular machines. Cell. 104:177-90.

Wahl MC, Will CL, Lührmann R. (2009) The spliceosome: design principles of a dynamic RNP machine. Cell. 136:701-18.

Warkocki Z, Odenwälder P, Schmitzová J, Platzmann F, Stark H, Urlaub H, Ficner R, Fabrizio P, Lührmann R. (2009) Reconstitution of both steps of Saccharomyces cerevisiae splicing with purified spliceosomal components. Nat Struct Mol Biol. 16:1237-43.

Will CL, Lührmann R. (2011) Spliceosome structure and function. Cold Spring Harb Perspect Biol. 3(7).

Will CL, Lührmann R. (2001) Spliceosomal UsnRNP biogenesis, structure and function. Curr Opin Cell Biol. 13:290-301. 
Woodman IL, Briggs GS, Bolt EL. (2007) Archaeal Hel308 domain V couples DNA binding to ATP hydrolysis and positions DNA for unwinding over the helicase ratchet. $\mathrm{J}$ Mol Biol. 374:1139-44.

Yang K, Zhang L, Xu T, Heroux A, Zhao R. (2008) Crystal structure of the beta-finger domain of Prp8 reveals analogy to ribosomal proteins. Proc Natl Acad Sci U S A. 105:13817-22.

Yang Q, Del Campo M, Lambowitz AM, Jankowsky E. (2007) DEAD-box proteins unwind duplexes by local strand separation. Mol Cell. 28:253-63.

Zhang L, Xu T, Maeder C, Bud LO, Shanks J, Nix J, Guthrie C, Pleiss JA, Zhao R. (2009) Structural evidence for consecutive Hel308-like modules in the spliceosomal ATPase Brr2. Nat Struct Mol Biol. 16:731-9.

Zhao C, Bellur DL, Lu S, Zhao F, Grassi MA, Bowne SJ, Sullivan LS, Daiger SP, Chen LJ, Pang CP, Zhao K, Staley JP, Larsson C. (2009) Autosomal-dominant retinitis pigmentosa caused by a mutation in SNRNP200, a gene required for unwinding of U4/U6 snRNAs. Am J Hum Genet. 85:617-27. 


\section{List of Figures and Tables}

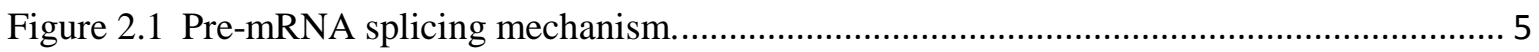

Figure 2.2 Consensus sequences of metazoan and yeast pre-mRNAs. ......................................... 5

Figure 2.3 Sequences and predicted secondary structures of the human spliceosomal snRNAs and

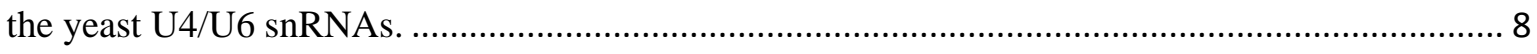

Figure 2.4 RNA/protein composition of the human spliceosomal U snRNPs. ............................... 9

Figure 2.5 Stepwise assembly and disassembly of the major spliceosome..................................... 11

Figure 2.6 Dynamics of the spliceosomal RNA-RNA network................................................. 13

Figure 2.7 Diagram of conserved sequence motifs of DEAD-box RNA helicases and their

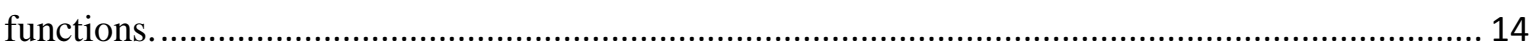

Figure 2.8 Sequence and structural organization of the conserved motifs of RNA helicases......... 17 Figure 2.9 Interactions of conserved motifs of SF1 and SF2 helicases with ATP and nucleic acid substrates.

Figure 2.10 Proposed models of helicase translocation............................................................ 19

Figure 2.11 Two distinct modes of RNA duplex unwinding by processive (DExH-box) and non-

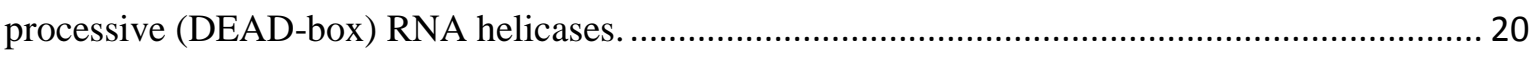

Table 2.1 Examples of SF1 and SF2 RNA helicase subfamilies from S.cerevisiae.....................16 


\section{Abbreviations}

\begin{tabular}{|c|c|}
\hline 3'ss & 3'splice site \\
\hline 5'ss & 5'splice site \\
\hline ATP & adenosine triphosphate \\
\hline $\mathrm{bp}$ & base pair(s) \\
\hline BPS & branch-point sequence \\
\hline DNA & Desoxyribonucleic acid \\
\hline $\mathrm{DExD} / \mathrm{H}$ & consensus sequence of helicases \\
\hline ds & double stranded \\
\hline ER & endoplasmic reticulum \\
\hline $\mathrm{kDa}$ & kilo Dalton \\
\hline$\mu \mathrm{M}$ & micro molar \\
\hline mRNA & messenger RNA \\
\hline MS & mass spectrometry \\
\hline $\mathrm{nM}$ & nanomolar \\
\hline NTP & nucleosid-5'-triphosphate \\
\hline oligo & oligonucleotide \\
\hline pre-mRNA & precursor messenger RNA \\
\hline RNA & ribonucleic acid \\
\hline RNase & Ribonuclease \\
\hline RNP & ribonucleoprotein \\
\hline RRM & RNA recognition motif \\
\hline S. cerevisiae & Saccharomyces cerevisiae \\
\hline $\mathrm{SR}$ & Serine Arginine rich \\
\hline ss & single stranded \\
\hline $\mathrm{U}$ & snRNA uridine-rich small nuclear RNA \\
\hline $\mathrm{U}$ & snRNP uridine-rich small nuclear \\
\hline
\end{tabular}




\section{Acknowledgements}

Here, I would like to take these last words to thank people who have supported and helped me during last years, especially those from whom I learned, and those who contributed to this work. I express my sincere to all members of the department of Cellular Biochemistry at Max Plank Institute of Biophysical Chemistry, for providing a very professional and friendly environment with the excellent research infrastructure.

In particular, I am very grateful to Prof. Reinhard Lührmann for all the supports and advices during these years. This work would not have succeeded without his excellent supervision and scientific management, which has always been an inspiration to me. I am honored to have Prof. Reinhard Jahn and Prof. Ralf Ficner as members of the PhD committee, and I would like to thank for their helpful comments on the project during the progress reports.

Very special thanks to Prof. Markus Wahl and Dr. Cindy Will for the very friendly advices and all the constructive discussions, enormous helps and outstanding collaboration in this work. In this project, I have been fortunate to have the privilege of collaborating with the group of Prof. Henning Urlaub, Dr. He-Hsuan Hsiao and Katharina Kramer for the analyses of RNA-protein crosslinks, for which I am very grateful.

I have been fortunate to work with Dr. Vlad Pena and Karine Santos during this project which led to outstanding results. I greatly appreciate the discussions and scientific helps from Dr. Klaus Hartmuth, Dr. Patrizia Fabrizio, Dr. Berthod Kastner and Dr. Kum-Loong Boon, Dr. Olex Dybkov, Dr. Prakash Dube, Dr. Homa Ghalei, Dr. Jana Schmitzová, and Dr. Gert Weber.

Many thanks to our kind and experienced technicians, Gabi Heyne, wiebke behrens-kranz, Thomas Conrad, Irene Öchsner and Hossein Kohansal, for their excellent assistance. I am thankful to secretary of the department, Juliane Moses for kindly solving every problem.

Many thanks to my former and present lab friends Marieke, Marc, Cyrille, Pinghui, Zbigniew, Boon, Sergey, Peter, Cornelius and all my friends and colleagues who kindly shared their moments with me at the department.

I deeply admire the excellent and competitive scientific environment provided by coordination office of the IMPRS program for Molecular Biology and its faculty members. In particular, I express my gratitude to Dr. Steffen Burkhardt for his outstanding coordination and his helps and advices.

Finally, I would never be able to conclude my $\mathrm{PhD}$ without the continuous support and helps of my kind family and my dear wife Ala. 


\section{Original Publications}

This thesis is based on the following articles, which are referred to in the text by the journal initials (in bold, italic):

1. Mozaffari-Jovin S, Santos KF, Hsiao HH, Will CL, Urlaub H, Wahl MC, Lührmann R. (2012) The Prp8 RNase H-like domain inhibits Brr2-mediated U4/U6 snRNA unwinding by blocking Brr2 loading onto the U4 snRNA. Genes Dev. 26:2422-34.

http://intl.genesdev.org/content/26/21/2422.abstract

DOI: $10.1101 / \mathrm{gad} .200949 .112$

2. Santos KF ${ }^{*}$, Jovin SM* , Weber G, Pena V, Lührmann R, Wahl MC. (2012) Structural basis for functional cooperation between tandem helicase cassettes in Brr2-mediated remodeling of the spliceosome. PNAS U S A. 109:17418-23.

http://www.pnas.org/content/109/43/17418.abstract

DOI: $10.1073 /$ pnas. 1208098109

3. Pena V*, Jovin SM* , Fabrizio P, Orlowski J, Bujnicki JM, Lührmann R, Wahl MC. (2009) Common design principles in the spliceosomal RNA helicase Brr2 and in the Hel308 DNA helicase. Mol Cell. 35:454-66.

http://www.cell.com/molecular-cell/abstract/S1097-2765(09)00552-8

DOI:10.1016/j.molcel.2009.08.006

4. Mozaffari-Jovin $\mathbf{S}^{*}$, Wandersleben $\mathrm{T}^{*}$, Santos $\mathrm{KF}^{*}$, Will CL, Wahl MC, Lührmann R. Mechanism of Dual Regulation of Spliceosomal Helicase Brr2 by the Prp8 Jab1 Domain and Links to Retinal Disease. Submitted manuscript for publication in peer-reviewed journal.

http://www.sciencemag.org/content/341/6141/80.short

DOI: $10.1126 /$ science. 1237515

* Equal contribution 


\section{Public presentations}

Part of this work was presented as oral presentation at scientific meetings:

1. Dec 2012: Seminar at the Centre for Genomic Regulation (CRG), Barcelona, Spain

2. Dec 2012: Cell Symposia: Functional RNAs, Sitges, Spain

3. Oct 2012: $7^{\text {th }}$ meeting of the study group RNA biochemistry, Bonn, Germany

4. Sep 2012: $1^{\text {st }}$ Polish-German Biochemical Societies Joint Meeting, Poznań/Poland

5. May 2012: $17^{\text {th }}$ Annual Meeting of the RNA Society. Ann Arbor, Michigan, USA.

6. April 2012: Frontiers Symposium in BioScience, Buenos Aires, Argentina

7. March 2012: EURASNET-Symposium, Trieste, Italy

8. March 2012: Seminar at the IGBMC in Strasbourg, France

9. March 2012: Keystone Symposia on Molecular and Cellular Biology in Santa Fe, New Mexico, USA

10. Oct 2011: Einweihung Leibniz Graduiertenschule in Berlin/opening ceremony of the Leibniz Graduate School, Berlin, Germany

Part of this work was presented as poster at scientific meetings:

1. Sep 2011: International Fall Meeting of the German Society for Biochemistry and Molecular Biology (GBM), Frankfurt, Germany

2. Sep 2010: $7^{\text {th }}$ International symposium: Horizons in Molecular Biology, Göttingen, Germany

3. Sep 2009: $6^{\text {th }}$ International symposium: Horizons in Molecular Biology, Göttingen, Germany

And at other scientific events in Göttingen, Germany 